\title{
Análise de desempenho de interfaces de rede virtualizadas com Napi
}

\author{
Eduardo Hideo Kuroda
}

\author{
DisSERTAÇÃO DE MESTRADO APRESENTADA \\ $\mathrm{AO}$ \\ Instituto DE MATEMÁticA E EstatísticA \\ DA \\ UniversidADE DE SÃO PAUlO \\ PARA \\ OBTENÇÃO DO TÍTULO \\ $\mathrm{DE}$ \\ Mestre em CiênCiA dA ComputaÇÃo
}

\begin{abstract}
Programa: Mestrado em Ciência da Computação
Orientador: Prof. Dr. Daniel Macêdo Batista
\end{abstract}

Durante o desenvolvimento deste trabalho o autor recebeu auxílio financeiro da Comissão Europeia e da Coordenação de Aperfeiçoamento de Pessoal de Nível Superior 
Análise de desempenho de interfaces de rede virtualizadas com Napi

Esta é a versão original da dissertação elaborada pelo candidato Eduardo Hideo Kuroda, tal como submetida à Comissão Julgadora. 


\section{Resumo}

Em ambientes virtualizados, como nuvens computacionais, a capacidade efetiva de transmissão de dados via rede tende a ser inferior à de ambientes não virtualizados quando aplicações que fazem uso intensivo da rede são executadas. Uma das principais causas para essa diferença na capacidade de transmissão é a arquitetura da virtualização de rede, que adiciona passos para o sistema operacional transmitir e receber um pacote. Esses passos adicionais acarretam em maior utilização de memória e de processamento. Em ambientes virtualizados com o sistema operacional GNU/Linux, a New Application Programming Interface (NAPI) é utilizada para reduzir os impactos negativos da virtualização por meio de agregação de interrupções. Nesta dissertação de mestrado, são estudados mecanismos que modificam a configuração da NAPI. Experimentos mostram que esses mecanismos afetam o desempenho de máquinas virtuais e tem consequências diretas nas aplicações que fazem uso intensivo de rede e que são executadas em ambientes com os softwares de virtualização Xen, VMware e VirtualBox.

Palavras-chave: computação em nuvem, virtualização de rede, agregação de interrupções, NAPI 


\section{Abstract}

In virtualized environments, such as cloud computing, the effective capacity of data transmission via network cards tends to be lower than that in non-virtualized environments, when networkintensive applications are executed. A major cause for this difference in the transmission capacity is the architecture of network virtualization, which adds some steps to be performed by the system when packets are transmitted or received. These additional steps cause more memory and processing usage. In virtualized environments with the GNU/Linux operating system, the New Application Programming Interface (NAPI) is used to reduce the negative impacts of virtualization through interrupt coalescence. In this dissertation, mechanisms that modify the configuration of NAPI are studied. Experiments show that these mechanisms affect the performance of virtual machines and have direct effects in applications that make intensive use of the network in environments with Xen, VMware and VirtualBox.

Keywords: cloud computing, network virtualization, interrupt coalescence, NAPI 


\section{Sumário}

Lista de Figuras $\quad$ vii

$\begin{array}{lc}\text { Lista de Tabelas } & \text { ix }\end{array}$

1 Introdução $\quad 1$

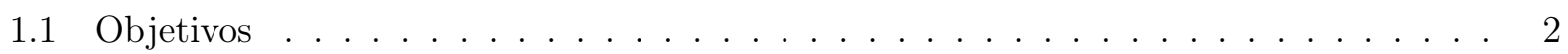

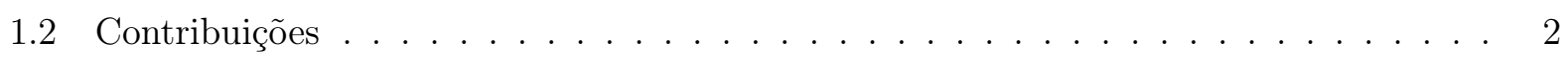

1.3 Organização da Dissertação . . . . . . . . . . . . . . . . . . . . . . . . 2

2 Conceitos $\quad 3$

2.1 Arquitetura de $\mathrm{E} / \mathrm{S}$ em Computadores . . . . . . . . . . . . . . . . . . 3

2.2 Computação em Nuvem . . . . . . . . . . . . . . . . . . . . . . . . . . . 4

2.3 Virtualização . . . . . . . . . . . . . . . . . . . . 6

2.3.1 Virtualização de Computadores . . . . . . . . . . . . . . . . . 6

2.3.2 Virtualização de Dispositivos de E/S . . . . . . . . . . . . . . . . . . 7

2.3.3 Virtualização do Dispositivo de Rede . . . . . . . . . . . . . . . . . . . . . . . 9

2.4 Interrupções de Hardware X Interrupções de Software . . . . . . . . . . . . . . . . 11

2.5 Agregação de Interrupções . . . . . . . . . . . . . . . . . . . . . . . . . . . . 12

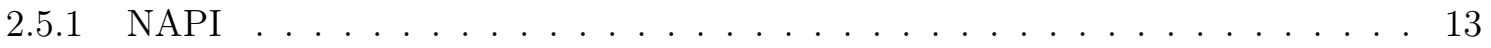

2.6 Agregação de Interrupções na Transmissão x Recepção . . . . . . . . . . . . . . . . . . 14

3 Revisão Bibliográfica $\quad 17$

3.1 Resumo Sintetizado . . . . . . . . . . . . . . . . . . . . . . . . . 17

3.2 Resumo Conclusivo . . . . . . . . . . . . . . . . . . . . . . . . . 21

4 Experimentos $\quad 23$

4.1 Banda X Limite . . . . . . . . . . . . . . . . . . . . . . . . . . . 23

4.2 Análise de Desempenho com Diferentes Hypervisors . . . . . . . . . . . . . . 28

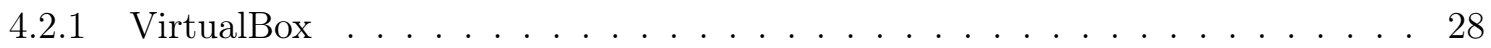

4.2 .2 VirtualBox com Afinidade de CPU . . . . . . . . . . . . . . . 32

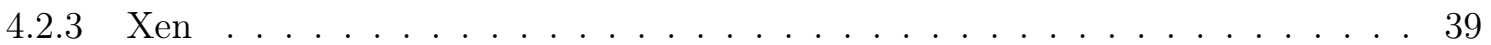

$4.2 .4 \quad$ VMware . . . . . . . . . . . . . . . . . . . . . . . 41

4.3 Análise dos Resultados . . . . . . . . . . . . . . . . . . . . . . 42

5 Conclusões $\quad 45$

5.1 Sugestões para Pesquisas Futuras . . . . . . . . . . . . . . . . . . . . 45 
vi SUMÁRIO

Referências Bibliográficas 


\section{Lista de Figuras}

2.1 Estrutura de um computador segundo o modelo de von Neumann (traduzida de [Sta10]) 3

2.2 Três técnicas para operações de E/S (traduzida de [Sta10]) . . . . . . . . . . . . . . 5

2.3 Compartilhamento de um dispositivo de $\mathrm{E} / \mathrm{S}$ na virtualização em nível de sistema operacional . . . . . . . . . . . . . . . . . . . . . . . . . . 8

2.4 Compartilhamento de um dispositivo de E/S na virtualização que utiliza hypervisors 8

2.5 Ponte virtual criada no Xen (traduzida de [Eas07]) . . . . . . . . . . . . . . . . . . . 10

2.6 Arquitetura da rede virtual no Xen (simplificada e traduzida de [STJP08]) . . . . . . 11

2.7 Taxa de transferência para diferentes dispositivos de E/S (traduzida e adaptada de [Sta10]) . . . . . . . . . . . . . . . . . . . . . . . . . . 12

2.8 Fluxograma do funcionamento da NAPI . . . . . . . . . . . . . . . . . . . . . . . . . 13

4.1 Taxa de recepção de pacotes com protocolo TCP . . . . . . . . . . . . . . . . . . . . 24

4.2 Quantidade de pacotes recebidos pelo driver com protocolo TCP . . . . . . . . . . . 24

4.3 Taxa de recepção de pacotes com protocolo UDP . . . . . . . . . . . . . . . . . . . 25

4.4 Quantidade de pacotes recebidos pelo driver com protocolo UDP . . . . . . . . . . 25

4.5 Taxa de recepção de pacotes com protocolo UDP modificando o buffer de recepção $\quad$ • 26

4.6 Quantidade de pacotes recebidos pelo driver com protocolo UDP modificando o buffer de recepção . . . . . . . . . . . . . . . . . . . . . . . . . . . . . . . . 26

4.7 Taxa de recepção no VirtualBox . . . . . . . . . . . . . . . . . . . . . . . . . . . . . . 29

4.8 Quantidade de pacotes recebidos pelo driver no VirtualBox . . . . . . . . . . . . . . 29

4.9 Uso da CPU pelas interrupções de software no VirtualBox . . . . . . . . . . . . . . . 30

4.10 Uso da CPU no VirtualBox . . . . . . . . . . . . . . . . . . . . . . . . . . . . . 30

4.11 Uso da CPU do ponto de vista da máquina física no VirtualBox . . . . . . . . . . . . 31

4.12 Taxa de recepção no VirtualBox com afinidade de CPU . . . . . . . . . . . . . . . . 32

4.13 Quantidade de pacotes recebidos pelo driver no VirtualBox com afinidade de CPU . 33

4.14 Uso da CPU do ponto de vista da máquina física no VirtualBox com afinidade de CPU 33

4.15 Quantidade de pacotes processados por ciclo de varredura com taxa de transmissão de $700 \mathrm{Mbits} / \mathrm{s}$. . . . . . . . . . . . . . . . . . . . . . . . . . . 34

4.16 Quantidade de pacotes processados por ciclo de varredura com taxa de transmissão de $800 \mathrm{Mbits} / \mathrm{s}$. . . . . . . . . . . . . . . . . . . . . . . . . . . . . . . 34

4.17 Quantidade de interrupções de hardware geradas pela placa de rede virtual no VirtualBox . . . . . . . . . . . . . . . . . . . . . . . . . 35

4.18 Quantidade de pacotes processados por ciclo de varredura com taxa de transmissão de 1000 Mbits $/ \mathrm{s}$. . . . . . . . . . . . . . . . . . . . . . . . . . 36 
4.19 Uso da CPU pelas interrupções de software no VirtualBox com afinidade de CPU . . 37

4.20 Uso da CPU no VirtualBox com afinidade de CPU . . . . . . . . . . . . . . . . . 37

4.21 Taxa de recepção no Xen . . . . . . . . . . . . . . . . . . . . . . . 39

4.22 Quantidade de pacotes recebidos pelo driver no Xen . . . . . . . . . . . . . 40

4.23 Uso da CPU no Xen . . . . . . . . . . . . . . . . . . . . . . . . . . 40

4.24 Taxa de recepção no VMware . . . . . . . . . . . . . . . . . . . . . . . . . 41

4.25 Quantidade de pacotes recebidos pelo driver no VMware . . . . . . . . . . . . . . . 41

4.26 Uso da CPU no VMware . . . . . . . . . . . . . . . . . . . . . . . 4 42

4.27 Comparação dos resultados com diferentes hypervisors . . . . . . . . . . . . . . 44 


\section{Lista de Tabelas}

2.1 Parâmetros para agregação de interrupções . . . . . . . . . . . . . . . . . . . 12 


\section{Capítulo 1}

\section{Introdução}

A computação em nuvem é um conceito que refere-se tanto a aplicações fornecidas como serviços por meio da Internet, como também a sistemas de hardware e software dos CPDs (Centros de Processamento de Dados) que fornecem os serviços através de técnicas de virtualização de computadores $\left[\mathrm{AFG}^{+}\right.$09]. Quando uma infraestrutura computacional é oferecida como serviço, recursos computacionais devem ser alocados a qualquer momento de acordo com os requisitos do usuário $\left[\mathrm{GED}^{+} 11\right]$.

A vantagem da computação em nuvem para os clientes pode ser melhor compreendida com um simples exemplo. Considere uma empresa de comércio eletrônico que queira garantir um tempo de resposta aceitável para a sua página em qualquer época do ano. Nas vésperas do Natal, do dia Crianças, do dia dos Pais e do dia das Mães, essa empresa alugaria uma quantidade $x$ de processadores de um provedor de computação em nuvem. Em outras épocas do ano entretanto, esse aluguel pode ser reduzido para, por exemplo, $x / 16$, já que a quantidade de acessos fora de épocas festivas tende a ser reduzida. Nesse cenário há ainda a vantagem de que o cliente pode pagar apenas pelo que usa, da mesma forma que acontece com outros serviços como telefonia, água e energia elétrica.

Na grande maioria das vezes a virtualização é utilizada para dividir, virtualmente, um recurso físico com grande capacidade, em recursos menores. Quando o recurso compartilhado é um computador, os recursos menores são chamados de máquinas virtuais [ $\left.\mathrm{BDF}^{+} 03\right]$. Essa divisão em recursos menores pode ser modificada em tempo de execução permitindo que o provedor de recursos virtuais adeque as máquinas virtuais à demanda e aos requisitos de QoS (do inglês Quality of Service - Qualidade de Serviço) dos clientes $\left[\mathrm{AFG}^{+}\right.$09]. Nesse cenário há ganhos do lado do cliente, que não precisa adquirir equipamentos mais potentes para atender apenas um pico momentâneo de demanda, e há ganhos do lado do provedor, que pode gerenciar os seus recursos de modo que fiquem ligados apenas aqueles que estão de fato servindo a algum cliente. Além disso o provedor pode utilizar mecanismos que otimizam a utilização dos recursos físicos de modo a aproveitá-los da melhor forma possível ao reduzir a quantidade de tempo em que eles ficam ociosos.

Apesar das máquinas virtuais viabilizarem a flexibilidade exibida pela computação em nuvem, elas ainda têm um desempenho abaixo das máquinas físicas quando são executadas aplicações que usam muito a rede [WCC ${ }^{+}$08] [EF10] [Liu10] [WR12] [Rix08]. Uma das principais causas é a forma com que o hypervisor, módulo que gerencia as máquinas virtuais, intermedia a comunicação das máquinas virtuais com os dispositivos físicos de rede. Diferentemente dos computadores físicos, as máquinas virtuais necessitam executar alguns passos adicionais para transmitir ou receber um pacote de informação, o que implica em um custo adicional no processamento e pode levar a variações na capacidade da rede vista pelas aplicações $\left[\mathrm{WCC}^{+}\right.$08] [EF10] [Liu10] [WR12] [Rix08].

Uma proposta para reduzir a carga no processamento da rede em máquinas virtuais, em relação às máquinas físicas, é adotar estratégias que agreguem as interrupções geradas para a transmissão/recepção de pacotes [Sal07] [DXZL11]. Uma estratégia simples é agregar as interrupções por intervalo de tempo ou por quantidade de pacotes. Dessa forma, o dispositivo de rede deixa de gerar interrupções a cada pacote que chega ou que é transmitido e passa a gerar uma única interrupção 
apenas de acordo com a configuração: após um intervalo de tempo, ou após uma certa quantidade de pacotes ser alcançada. Como apenas uma interrupção é gerada para um agrupamento de pacotes, isso reduz a quantidade de interrupções, porém, essa técnica pode levar a atrasos no processamento de pacote perceptíveis pela aplicação.

Atualmente, uma estratégia de agregação muito utilizada é a NAPI (New Application Programming Interface) [CRKH05], um conjunto de interfaces oferecido pelo núcleo Linux que os drivers dos dispositivos de rede implementam para agregar interrupções. Porém, há poucos estudos na área, principalmente quando consideramos dispositivos virtuais. Neste trabalho de mestrado realizamos um estudo aprofundado da NAPI e identificamos quais parâmetros influenciam o desempenho em termos de capacidade efetiva da rede e do uso da $C P U$ (do inglês Central Processing Unit - Unidade Central de Processamento).

\section{$1.1 \quad$ Objetivos}

Na NAPI, quando uma grande quantidade de pacotes é enviada para o dispositivo de rede, ao invés do dispositivo enviar uma interrupção ao driver para cada pacote que chega, o driver desabilita as interrupções na chegada do primeiro pacote e processa continuamente os próximos pacotes. Esse processamento contínuo dos pacotes é chamado varredura.

A NAPI possui um parâmetro chamado limite. Esse parâmetro limita a quantidade de pacotes processada pelo sistema a cada ciclo de varredura. Os efeitos de diferentes valores de limite são estudados nos trabalhos de Corbet [Cor05] e Salah [SEB05], porém, apenas considerando dispositivos físicos. Assim, o objetivo desse trabalho é elaborar um mecanismo que escolha o melhor valor para o parâmetro limite da NAPI, no qual o sistema tenha um bom desempenho tanto em termos de uso de $C P U$ como na capacidade efetiva da placa de rede.

\subsection{Contribuições}

As principais contribuições desta dissertação são:

- Uma apresentação detalhada de conceitos relacionados com virtualização de placas de rede;

- Um estudo aprofundado sobre o comportamento dos dispositivos de rede virtuais usando NAPI. Estudos encontrados na literatura atualmente foram realizados apenas com dispositivos de rede físicos;

- Um mecanismo que define o melhor valor para o parâmetro limite da NAPI, considerando a capacidade efetiva da placa de rede e o uso de $C P U$ para os seguintes hypervisors: Xen, VMware e VirtualBox.

\subsection{Organização da Dissertação}

Esta dissertação está organizada da seguinte forma: no Capítulo 2, são apresentados os conceitos de dispositivos de Entrada e Saída (E/S), interrupções de hardware e software, virtualização de computadores, virtualização de rede, agregação de interrupções e computação em nuvem. No Capítulo 3 é apresentada uma revisão bibliográfica na área de virtualização de rede. No Capítulo 4 são apresentados os experimentos que avaliam os efeitos de diferentes valores de limite na NAPI. Por fim, no Capítulo 5 são apresentadas as conclusões do trabalho. 


\section{Capítulo 2}

\section{Conceitos}

Esta dissertação estuda aspectos tanto de hardware, como de software de sistemas operacionais em ambientes virtualizados. A seguir, descreveremos os mecanismos de $\mathrm{E} / \mathrm{S}$ de computadores que seguem o modelo de von Neumann e, em seguida, mostraremos como isso se aplica em plataformas de computação virtualizada como as de computação em nuvem.

\subsection{Arquitetura de E/S em Computadores}

Um computador, segundo o modelo de von Neumann [Sta10], é formado por uma memória principal, uma unidade central de processamento e dispositivos de E/S como mostra a Figura 2.1. Nesse modelo genérico, a unidade central de processamento comunica-se com a memória e com os dispositivos de $\mathrm{E} / \mathrm{S}$, sendo que esses dois últimos não comunicam-se diretamente entre si. Cada dispositivo de $\mathrm{E} / \mathrm{S}$ do computador é controlado por um módulo para E/S. Este módulo de E/S é necessário para que o processador possa se comunicar com um ou mais dispositivos de E/S. Os dispositivos de $\mathrm{E} / \mathrm{S}$ possuem vários métodos de operação, diferentes formatos, comprimento de palavras e velocidade de transferência, o que faz cada módulo ter um protocolo específico para um tipo de dispositivo.

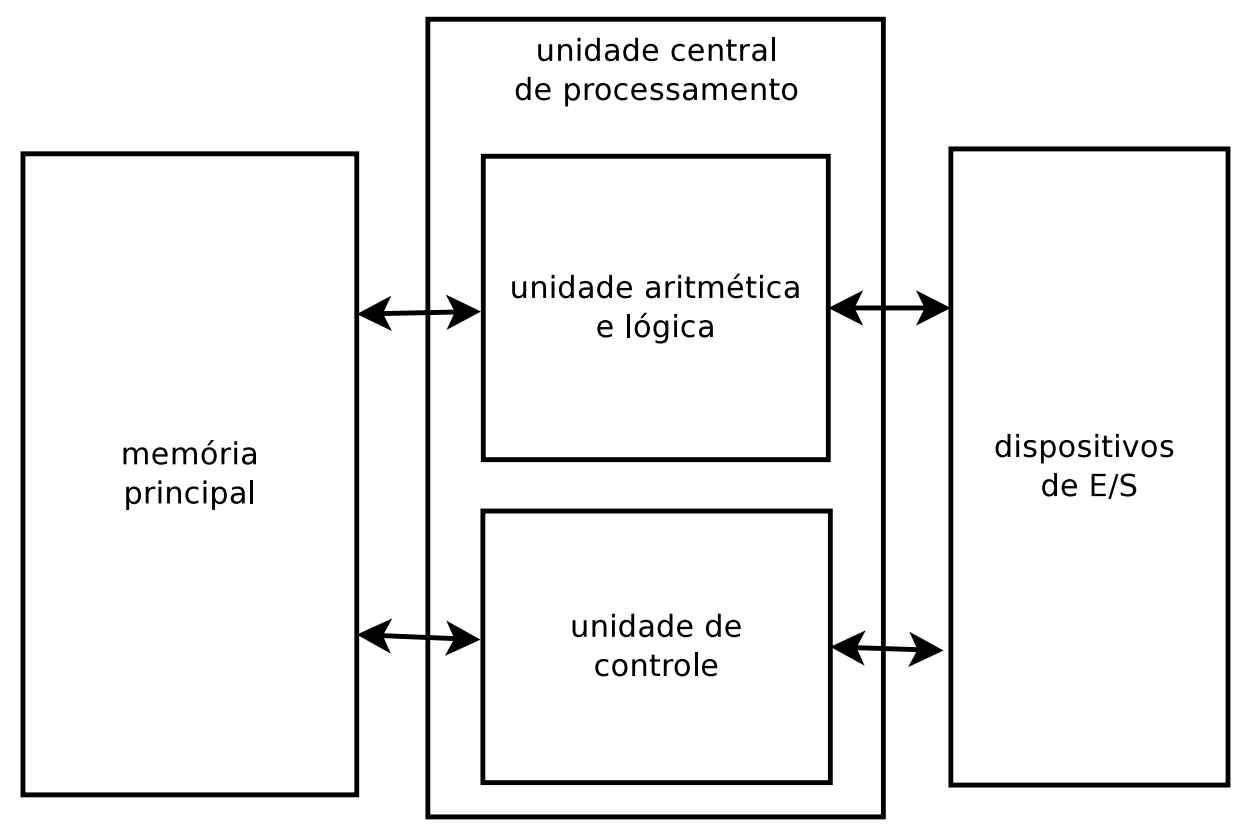

Figura 2.1: Estrutura de um computador segundo o modelo de von Neumann (traduzida de [Sta10])

Existem três técnicas possíveis para operações de E/S: E/S programada (varredura), interrupção dirigida a E/S e DMA (do inglês Direct Memory Access - Acesso Direto a Memória). 
- Na E/S programada, também chamada de varredura, dados são transferidos entre o processador e o módulo de E/S. O processador executa um programa e fornece a este o controle direto das operações de $\mathrm{E} / \mathrm{S}$. Um problema com essa estratégia é o intervalo de tempo que o processador precisa esperar para o dispositivo de E/S estar pronto. Dentro desse intervalo, muitas instruções poderiam ser processadas;

- Na interrupção dirigida a E/S, um programa emite um comando requisitando E/S e continua executando outras instruções. O módulo de $\mathrm{E} / \mathrm{S}$ gera uma interrupção de hardware quando o dispositivo estiver preparado e o processador trata essa interrupção. Como o processador não espera ociosamente o dispositivo estar pronto, é possível processar uma quantidade de instruções maior do que na $\mathrm{E} / \mathrm{S}$ programada quando algum dispositivo de $\mathrm{E} / \mathrm{S}$ é acessado;

- No DMA, um módulo chamado DMA é incluído no sistema. O módulo é um processador especializado em E/S que recebe o controle das operações de E/S para mover um grande bloco de dados usando a memória principal. Quando o módulo conclui uma operação, uma interrupção de hardware é gerada para ser tratada pelo processador. Nota-se que o processador não participa ativamente nessa técnica como nas anteriores, o que reduz o custo de processamento.

Na Figura 2.2, é possível observar os fluxogramas das três técnicas sendo aplicadas para receber um bloco de dados de um dispositivo de E/S. Tanto na varredura como na interrupção dirigida a $\mathrm{E} / \mathrm{S}$, percebe-se que o processador participa de todo processo, enquanto que no $D M A$, como o dispositivo consegue acessar diretamente a memória, a $C P U$ participa apenas na requisição de leitura e na recepção da interrupção do módulo de $D M A$, avisando que o bloco de dados foi copiado. Atualmente, a técnica de varredura é pouco usada, pois é desperdiçado muito tempo de processamento e sempre podem existir aplicações que necessitam de processamento. Já a interrupção dirigida a $\mathrm{E} / \mathrm{S}$ é normalmente usada para dispositivos de $\mathrm{E} / \mathrm{S}$ que transferem quantidades pequenas de informação e necessitam de pouco atraso, como o teclado e o mouse. O DMA é normalmente usado para dispositivos que transferem quantidades grandes de informações como o disco rígido e placas de rede.

\subsection{Computação em Nuvem}

A computação em nuvem é um paradigma de computação no qual serviços computacionais são requisitados por clientes e executados por provedores de serviços, na grande maioria das vezes remotamente através da virtualização de computadores. Os clientes nesse paradigma pagam apenas pela quantidade de utilização dos serviços. A ideia da computação em nuvem é tornar a computação um serviço da mesma forma como acontece com a energia elétrica, ou seja, a infraestrutura deve ser transparente para o usuário que pagará apenas pela quantidade utilizada e que terá garantias de que seus requisitos de $Q o S$ serão atendidos. O termo computação em nuvem costuma ser usado para referir-se tanto a aplicações fornecidas como serviços por meio da Internet como também a sistemas de hardware e software dos CPDs (Centro de Processamento de Dados) que fornecem os serviços $\left[\mathrm{AFG}^{+} 09\right]$.

Existem várias classificações para os serviços fornecidos na computação em nuvem. Uma das mais difundidas divide os serviços em três classes: software como serviço (SaaS - Software as a Service), plataformas como serviço (PaaS - Platform as a Service), e infraestruturas como serviço (IaaS - Infrastructure as a Service).

Exemplificando:

- Nuvens que fornecem SaaS oferecem aplicações como serviço para o cliente. Como exemplo temos o Google Docs ${ }^{1}$ que fornece um software para edição de documentos como serviço e que pode ser acessado via navegador ou por aplicações dedicadas em dispositivos como celulares e tablets;

\footnotetext{
${ }^{1}$ http://docs.google.com
} 


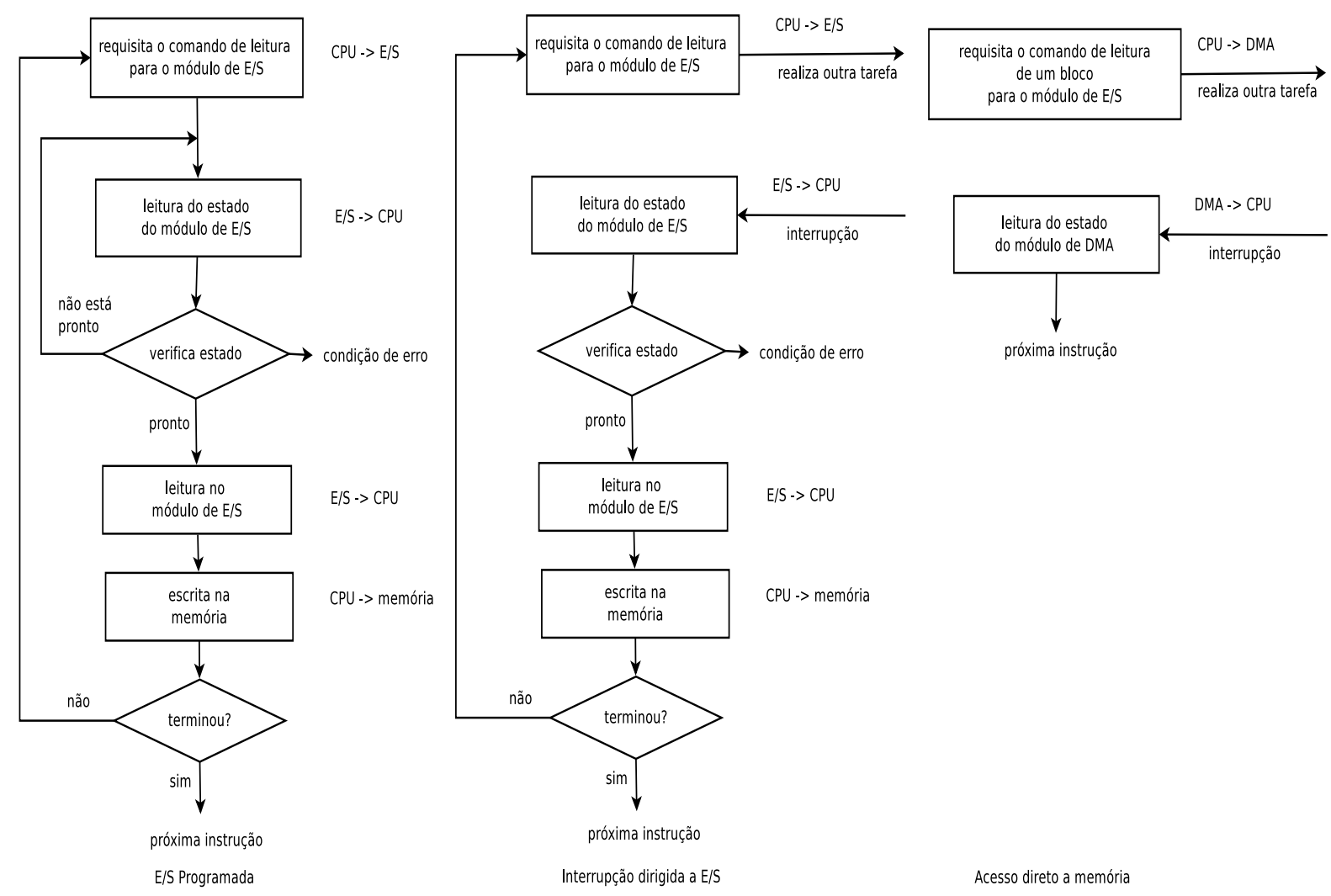

Figura 2.2: Três técnicas para operações de E/S (traduzida de [Sta10])

- Nuvens que fornecem PaaS oferecem plataformas nas quais o cliente pode criar e implantar suas aplicações. O Google App Engine $e^{2}$ e o Windows Azure ${ }^{3}$ são exemplos desse tipo de nuvem. O cliente de PaaS na grande maioria das vezes são desenvolvedores de aplicações, diferente dos clientes de SaaS que não precisam ter qualquer conhecimento de desenvolvimento de aplicações para utilizarem os serviços;

- IaaS oferecem infraestruturas computacionais ao cliente. Um exemplo desse tipo de nuvem é o Amazon $\mathrm{EC} 2^{4}$ que fornece uma infraestrutura computacional. Clientes de IaaS podem ser tanto desenvolvedores quanto administradores de sistemas que pretendem implantar um sistema já desenvolvido em uma plataforma virtual para reduzir os custos com TI das suas empresas.

Nesta dissertação, focamos no fornecimento de infraestrutura, em específico, computadores como serviço (IaaS). Cada serviço pode receber várias requisições para hospedar programas de desenvolvedores e, nesse caso, terá que implantá-los na infraestrutura. Quando um cliente, em algum momento, faz uma requisição para executar esse programa, a nuvem executa o programa internamente e repassa o resultado ao cliente. Para que isso seja possível, a infraestrutura de nuvem contém vários nós, os quais são recursos físicos, como computadores ou mesmo CPDs inteiros, que contêm e controlam várias máquinas virtuais usando alguma técnica de virtualização. Cada requisição para implantar ou executar um programa é feita oferecendo as máquinas virtuais as quais estão contidas na infraestrutura.

\footnotetext{
${ }^{2}$ http://developers.google.com/appengine/

${ }^{3}$ http://www.windowsazure.com/en-us/

${ }^{4}$ http://aws.amazon.com/ec2/
} 


\subsection{Virtualização}

Na computação em nuvem, em particular quando fornecemos uma infraestrutura para implantar aplicações (IaaS), a adoção da virtualização, em relação a computadores que não adotam virtualização, melhora a utilização dos recursos e protege o computador de problemas que os softwares dos clientes possam causar [ $\left.\mathrm{WCC}^{+} 08\right]$. Por exemplo, em um cenário com máquinas sem virtualização, um erro de programação que cause um laço infinito pode consumir toda a $C P U$ do computador, atrapalhando todos os usuários daquela máquina. Em um cenário virtualizado, há um isolamento entre os recursos das máquinas virtuais o qual impede uma máquina virtual de usar recursos alocados para outra máquina virtual. Assim, a única máquina afetada no cenário é aquela utilizada pelo programador. Além disso, não é possível expandir a quantidade dos recursos sem permissão do administrador da nuvem, dando mais segurança e controle na infraestrutura em relação a infraestruturas sem virtualização. Além da segurança, outra consequência da virtualização, é o surgimento de um novo modelo de negócio chamado "pague somente quando usa", onde o cliente paga somente pelo tempo que o recurso é usado. Além disso, o cliente tem a impressão de estar utilizando um ambiente com recursos infinitos, já que é possível aumentar os recursos de uma máquina virtual sem interrupção do serviço e mais máquinas podem ser agregadas para prover o serviço [ $\left.\mathrm{AFG}^{+} 09\right]$.

Essas características beneficiam o provedor do serviço, que não precisará fornecer um recurso físico inteiro para cada cliente e terá maior segurança e tolerância a falhas, já que cada sistema é independente. Do lado do cliente, ele economizará dinheiro pelo novo modelo de negócio e terá recursos sob demanda.

Nos dispositivos de E/S, a virtualização permite a emulação de hardware. Em relação a flexibilidade, é possível mapear os dispositivos lógicos com as implementações físicas, garantindo uma maior portabilidade. Esse mapeamento pode também trazer novas funcionalidades ao recurso como: balanceamento da carga de trabalho e mascaramento das falhas.

\subsubsection{Virtualização de Computadores}

As nuvens normalmente são constituídas de computadores que estão ligados de alguma forma por uma rede. A virtualização de computadores divide um computador, geralmente com grande capacidade de processamento, em recursos menores chamados de máquinas virtuais de modo que cada uma age como se fosse um computador separado, podendo ter inclusive, diferentes sistemas operacionais $\left[\mathrm{BDF}^{+}\right.$03]. Segundo Walters, Chaudhary, Cha, Jr. e Gallo $\left[\mathrm{WCC}^{+} 08\right]$, as estratégias de virtualização podem ser divididas em 4 grandes categorias: virtualização completa, para-virtualização, virtualização em nível de sistema operacional e virtualização nativa.

Em ambientes virtualizados, o hypervisor é o software que fornece a plataforma para as máquinas virtuais e gerencia a execução delas. No hypervisor da virtualização completa, é feita a interceptação, tradução e execução das instruções sob demanda dos sistemas operacionais das máquinas virtuais. Nessa estratégia, o núcleo do sistema operacional que executa o hypervisor não necessita de modificações. Dentro dessa categoria de hypervisors estão o $\mathrm{KVM}^{1}$, o $\mathrm{Xen}^{2}$, o $\mathrm{VMware}^{3}$ e o VirtualBox ${ }^{4}$.

A para-virtualização também utiliza um hypervisor para gerenciar as máquinas virtuais, porém, ao invés desse ser um programa executado sobre um sistema operacional sem modificações, como na virtualização completa, ele trabalha diretamente no hardware e exige que o núcleo do sistema operacional da máquina física seja modificado. Assim, caso não exista o código-fonte do sistema, não é possível usar essa estratégia. Na para-virtualização, o hardware virtual consegue conversar diretamente com o dispositivo emulado. Isso garante uma sobrecarga mínima em relação a tentar emular o dispositivo real. Nessa categoria está incluído o Xen.

\footnotetext{
${ }^{1}$ http://www.linux-kvm.org/

${ }^{2}$ http://xen.org/

${ }^{3}$ http://www.vmware.com/

${ }^{4}$ http://www.virtualbox.org/
} 
A virtualização em nível de sistema operacional não utiliza um hypervisor. Ela modifica o núcleo do sistema isolando múltiplas instâncias do sistema operacional dentro de uma mesma máquina física. Nesse caso, como é feito apenas um isolamento entre as instâncias, estas ficam limitadas a usarem o mesmo sistema operacional. Uma vantagem e ao mesmo tempo desvantagem dessa categoria é o compartilhamento do núcleo entre as instâncias do sistema operacional. O compartilhamento do núcleo simplifica os mecanismos de compartilhamento de memória e o acesso a dispositivos físicos que em outras virtualizações necessitam da implementação de um canal de comunicação entre núcleos, adicionando uma carga extra no sistema. Por outro lado, como todas as instâncias dependem de um único núcleo, este se torna um ponto único de falha. Está incluído nessa categoria o OpenVZ ${ }^{5}$.

A virtualização nativa é uma virtualização completa "melhorada". Ela aproveita o hardware do processador que implementa mecanismos para otimizar a virtualização. Isto permite que múltiplos sistemas operacionais rodem sobre outro, sendo capazes de cada um acessar diretamente o processador do hospedeiro. Como exemplos temos o Xen, KVM, o VMware e o VirtualBox. Nota-se que o Xen é capaz virtualizar com a virtualização completa, nativa ou para-virtualização.

As virtualizações completa e nativa têm uma grande vantagem em relação às outras: não é necessário alterar o núcleo do sistema operacional da máquina hospedeira. Isto as tornam mais simples e mais portáveis já que sistemas operacionais com código fechado podem ser utilizados. A para-virtualização e a virtualização em nível de sistema operacional exigem uma modificação no núcleo da máquina hospedeira, porém, são as que tem um melhor desempenho pois elas têm acesso ao hardware físico. Comparando as duas, a virtualização em nível de sistema operacional é bem mais intrusiva e não permite a mudança do sistema operacional das máquinas virtuais $\left[\mathrm{PZW}^{+} 07\right]$ $\left[\mathrm{WCC}^{+} 08\right]$ [SBdSC] [CSYL10].

\subsubsection{Virtualização de Dispositivos de $\mathrm{E} / \mathrm{S}$}

Os dispositivos de E/S são instrumentos que recebem ou enviam dados para o sistema computacional como o mouse, o teclado e o monitor. Quando falamos em dispositivos físicos nos referimos ao dispositivo de $\mathrm{E} / \mathrm{S}$ como hardware, enquanto que dispositivos lógicos se referem ao dispositivo em forma lógica. Com a virtualização de computadores, os dispositivos de E/S sofreram modificações já que em um computador não há apenas um único sistema operacional, mas sim, várias máquinas virtuais com um sistema dentro de cada uma.

No trabalho de Rixner [Rix08], foi separada a virtualização de E/S em duas categorias: privada ou compartilhada. Na virtualização de E/S privada, cada dispositivo físico é associado a apenas uma única máquina virtual enquanto que na virtualização de $\mathrm{E} / \mathrm{S}$ compartilhada, o dispositivo é compartilhado por várias máquinas virtuais.

Comparando a virtualização de E/S privada com a compartilhada há uma subutilização na virtualização privada, pois enquanto uma máquina virtual não utiliza o dispositivo, outra poderia necessitar do seu uso. Por outro lado, o desempenho da virtualização compartilhada é pior já que divide o recurso com outras máquinas. Quando pensamos em aumentar o número de máquinas virtuais, o custo da virtualização privada cresce absurdamente (com 10 máquinas virtuais teríamos que ter 10 dispositivos físicos enquanto que na virtualização compartilhada, talvez até um dispositivo poderia ser o suficiente para resolver o problema).

Normalmente, a opção mais comum é que o dispositivo físico seja compartilhado entre as máquinas, tanto pela possibilidade de escalar como pelo custo. Porém, disponibilizar de maneira compartilhada o acesso a dispositivos físicos pode trazer muitos problemas de segurança e dificultar o monitoramento das informações [STJP08]. Problemas de segurança surgem porque o usuário de uma máquina virtual pode tentar o acesso a uma outra máquina virtual justamente através do recurso que está sendo compartilhado [Rix08]. O monitoramento é dificultado porque ferramentas comuns só fazem medições do dispositivo físico e como este está associado a várias máquinas virtuais, ficaria complexo separar as informações específicas de cada uma dentro do agregado [GED $\left.{ }^{+} 11\right]$.

\footnotetext{
${ }^{5}$ http://wiki.openvz.org/
} 
Para lidar com o problema de segurança causado pelo compartilhamento do dispositivo, na virtualização em nível de sistema operacional como o OpenVZ, o núcleo do sistema gerencia a utilização do dispositivo entre as máquinas virtuais como mostra a Figura 2.3. Nela três máquinas virtuais acessam o dispositivo de $\mathrm{E} / \mathrm{S}$ através do mesmo núcleo do sistema. Já em hypervisors como Xen, KVM e VMware, como cada máquina possui seu próprio núcleo, é muito complexo fazer o conjunto de núcleos gerenciar o dispositivo entre as máquinas. A solução foi restringir o acesso ao dispositivo físico para apenas uma máquina virtual ou para a máquina hospedeira e o acesso a esse dispositivo pelas outras máquinas virtuais é feito através dessa máquina. Como é possível ver na Figura 2.4, a máquina virtual 0 gerencia o dispositivo de $\mathrm{E} / \mathrm{S}$ enquanto que as máquinas virtuais 1 e 2 acessam o dispositivo se comunicando com o núcleo do sistema 0. Essa restrição traz uma perda de desempenho em relação a ambientes que não usam virtualização quando, por exemplo, o uso da placa de rede é intenso, porém, garante segurança já que é possível monitorar o tráfego de todas as máquinas através da máquina que gerencia o dispositivo [ $\mathrm{WCC}^{+} 08$ ] [EF10] [Liu10].

Em relação a monitoramento, cada hypervisor implementa seu próprio programa para monitorar os recursos de cada máquina virtual.

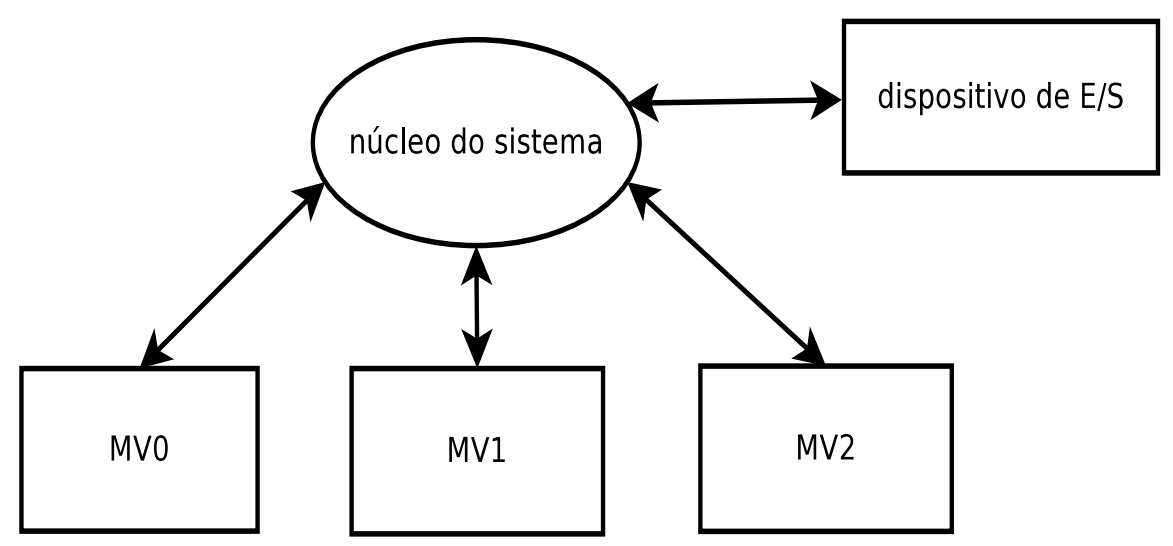

Figura 2.3: Compartilhamento de um dispositivo de $E / S$ na virtualização em nível de sistema operacional

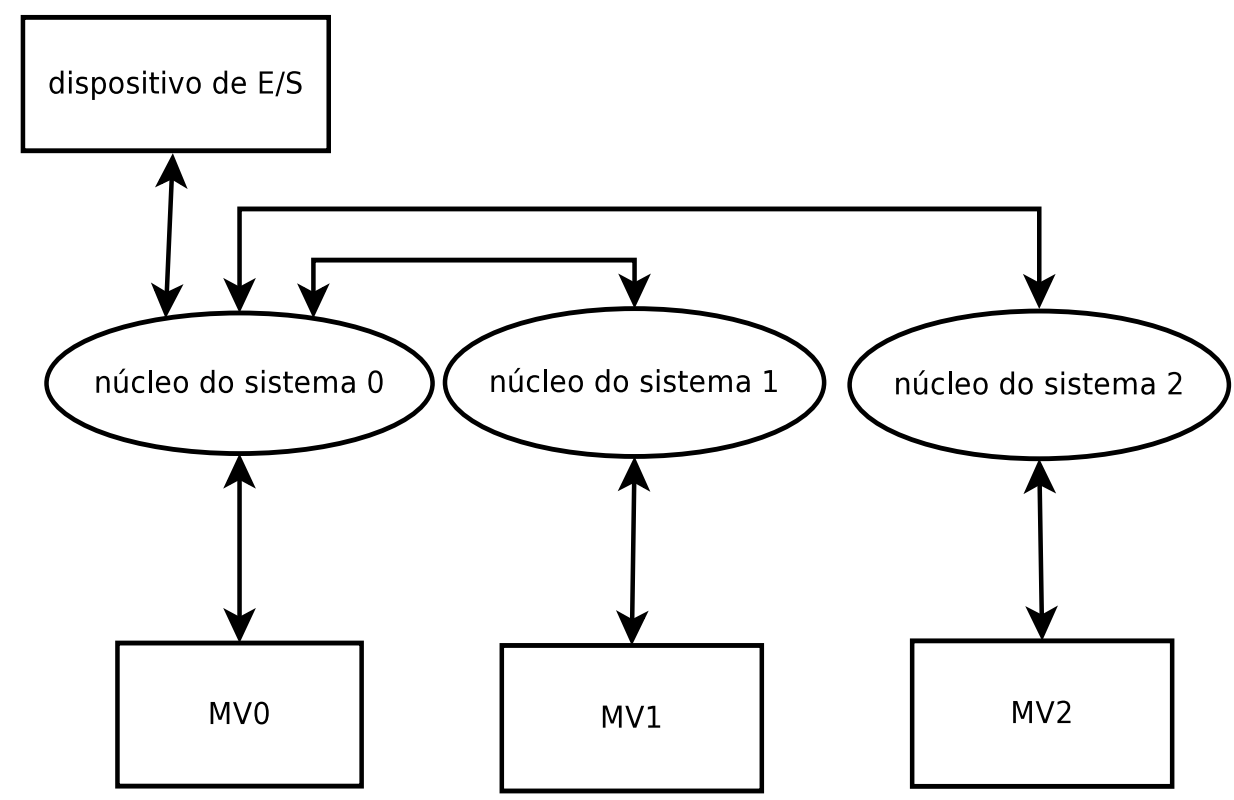

Figura 2.4: Compartilhamento de um dispositivo de $E / S$ na virtualização que utiliza hypervisors

No trabalho de Waldspurger e Rosenblum [WR12], foram feitas algumas menções sobre o uso de técnicas de virtualização de $\mathrm{E} / \mathrm{S}$ que desacoplam o dispositivo físico da sua implementação 
lógica. Dentre as vantagens, é citada a melhor utilização dos recursos e a economia de custos em relação a sistemas que estão com o dispositivo físico acoplado com a sua implementação lógica, pois vários sistemas podem aproveitar o mesmo recurso. Em relação a flexibilidade, é possível mapear os dispositivos físicos com as implementações lógicas, garantindo uma maior portabilidade. Esse mapeamento pode também trazer novas funcionalidades ao recurso como: balanceamento da carga de trabalho e mascaramento das falhas. A funcionalidade de suspender, migrar e continuar uma máquina virtual também é possível, pois com o dispositivo físico desacoplado da implementação lógica, é possível reconectar a máquina virtual em outra máquina física com uma configuração diferente. Outra funcionalidade trazida com a virtualização é a interposição e transformação das requisições virtuais de $\mathrm{E} / \mathrm{S}$. Isso permite que as requisições que passam pelo dispositivo lógico sejam transformadas. Em um exemplo de leitura e escrita no disco, além de simplesmente ler/escrever no disco, torna-se possível guardar uma cópia da informação antiga como cópia de segurança. Outra possibilidade é criptografar a informação quando alguém escrever no disco, dificultando outras pessoas de acessarem o seu conteúdo escrito.

\subsubsection{Virtualização do Dispositivo de Rede}

A virtualização do dispositivo de rede, que também é um dispositivo de E/S, tem algumas particularidades em relação a outros dispositivos. Segundo Rixner [Rix08], a complexidade de virtualizar a rede é muito maior pelo fato de muitas vezes não se conhecer o destino de uma informação, pois esse está fora do sistema, diferente por exemplo do disco rígido que só se comunica com o sistema. Outra dificuldade é a necessidade do sistema operacional estar preparado a qualquer momento para receber e responder ao tráfego da rede, diferentemente da virtualização de disco em que a leitura e escrita só ocorre quando requisitada pela máquina virtual.

Outra diferença é a taxa de transferência em relação a outros dispositivos de E/S, as placas de rede 10 Gigabit por exemplo transferem dados com um taxa $3 \mathrm{x}$ maior que os discos rígidos, como é possível ver na Figura 2.7 [Sta10].

\section{Virtualização da Rede no Xen}

Apesar desta subseção descrever a arquitetura de virtualização de rede específica do Xen, esta é utilizada por outros hypervisors como o KVM e o VMware [STJP08]. O Xen é um hypervisor de código aberto disponível para arquiteturas de máquina física x86, x86_64, IA64, ARM. Ele permite a virtualização nativa e para-virtualizada de sistemas operacionais Windows, Linux, Solaris e diversos outros sistemas baseados no BSD [Spe10].

No Xen, o dom0 ou domínio zero é a primeira máquina virtual iniciada. Ela tem certos privilégios que as outras máquinas virtuais não têm, como iniciar novas máquinas e acessar o hardware diretamente. Os domUs ou domínios do usuário são máquinas virtuais que, por padrão, não tem alguns privilégios que o dom0 tem, como o acesso direto ao hardware. Assim, é necessário um mecanismo para conseguir acessar o dispositivo de rede [Spe10].

No Xen, para todas as máquinas conseguirem acessar o dispositivo de rede ao mesmo tempo, existem dois tipos de configuração: ponte e roteador. Ambas as configurações seguem os conceitos dos equipamentos de mesmo nome que existem na interconexão de redes de computadores. Todos os dois tipos encaminham pacotes entre domínios baseados nas informações que os próprios pacotes contêm, porém a ponte se fundamenta nos dados da camada de enlace enquanto que o roteador se fundamenta nos dados da camada de rede [BM99]. Com a possibilidade de trafegar pacotes entre domínios, os domUs conseguem enviar e receber pacotes do dispositivo de rede tendo o dom0 como intermediário.

No artigo de Eastep [Eas07], foi descrita a implementação da configuração de ponte na qual uma ponte virtual (xenbro) é criada dentro do dom0, como é possível ver na Figura 2.5. Essa ponte está ligada na interface de rede física peth0. A interface vif0.0 está sendo usada para tráfegos de/para dom0 e as interfaces vifX.0, onde X é um valor maior que 0, estão sendo usadas para tráfegos de/para algum domU. Como é possível observar, todo pacote que é recebido ou transmitido 
para alguma máquina virtual tem que passar pela ponte dentro do dom0. A configuração de roteador é muito semelhante à configuração da ponte, porém, ao invés de existir uma ponte virtual, o dom0 possui um roteador virtual que é configurado para encaminhar pacotes IP (do inglês Internet Protocol - Protocolo Internet) entre os domínios e os domUs.

No experimento de James [Jam04], a ponte virtual e o roteador virtual foram comparados. Os resultados foram semelhantes tanto em termos de utilização da rede como na latência e no uso do processador.

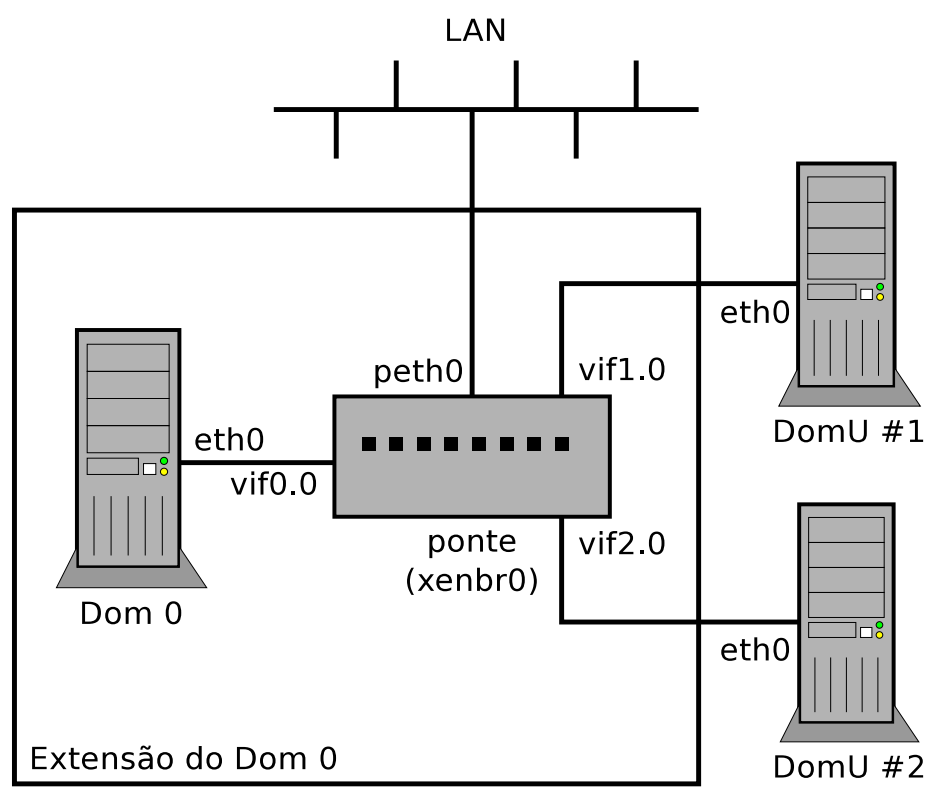

Figura 2.5: Ponte virtual criada no Xen (traduzida de [Eas07])

Na Figura 2.6 é apresentada a arquitetura da virtualização da rede usando ponte no Xen [STJP08]. Para transmitir/receber um pacote no domU é usado o canal de E/S (I/O channel). Esse canal evita que cada pacote tenha que ser copiado de um domínio a outro. Para tal, o domU compartilha algumas páginas de sua memória e informa a referência delas por esse canal para o outro domínio mapeá-las em seu espaço de endereço. Quando algum domínio envia algum pacote para essas páginas, uma notificação é enviada para o outro domínio.

O canal de E/S consiste de notificações de evento e um buffer de descrição em anel. A notificação de evento avisa que algum usuário do domínio deseja enviar informações. O buffer de descrição em anel guarda os detalhes de requisições entre o driver de frontend (netfront) que fica no interior do dom0 e o driver de backend (netback) que fica dentro de um domU.

Para o dom0 ter acesso às páginas da memória do $\operatorname{dom} U$ é necessário um mecanismo de permissão. Neste, o domU fornece páginas vazias da sua memória para serem usadas como buffer de E/S. Essas páginas são passadas como referência na descrição da requisição.

$\mathrm{Na}$ transmissão de pacotes, o domU coloca o pacote no buffer de $\mathrm{E} / \mathrm{S}$, as referências de suas páginas de memória no buffer de descrição e notifica o dom0 através de uma interrupção. O dom0 por sua vez, lê o buffer de descrição, mapeia as páginas recebidas no seu espaço de endereços e pede para transmiti-las através da ponte. Quando o dispositivo físico confirmar a transmissão, o domU libera as páginas do buffer de E/S.

Na recepção, o domU informa as possíveis páginas da memória que podem ser usadas como buffer de E/S ao dom0. Quando algum pacote chega pelo dispositivo físico, este envia uma interrupção de chegada de pacote à ponte dentro do dom0. A ponte então avisa o domU correto sobre a chegada de pacotes. O domo o copia para uma página da memória que foi fornecida pelo domU e envia uma interrupção para o mesmo. Quando o $\operatorname{dom} U$ recebe a interrupção, ele pega o conteúdo que está no buffer, envia para o seu sistema e libera as páginas fornecidas. 


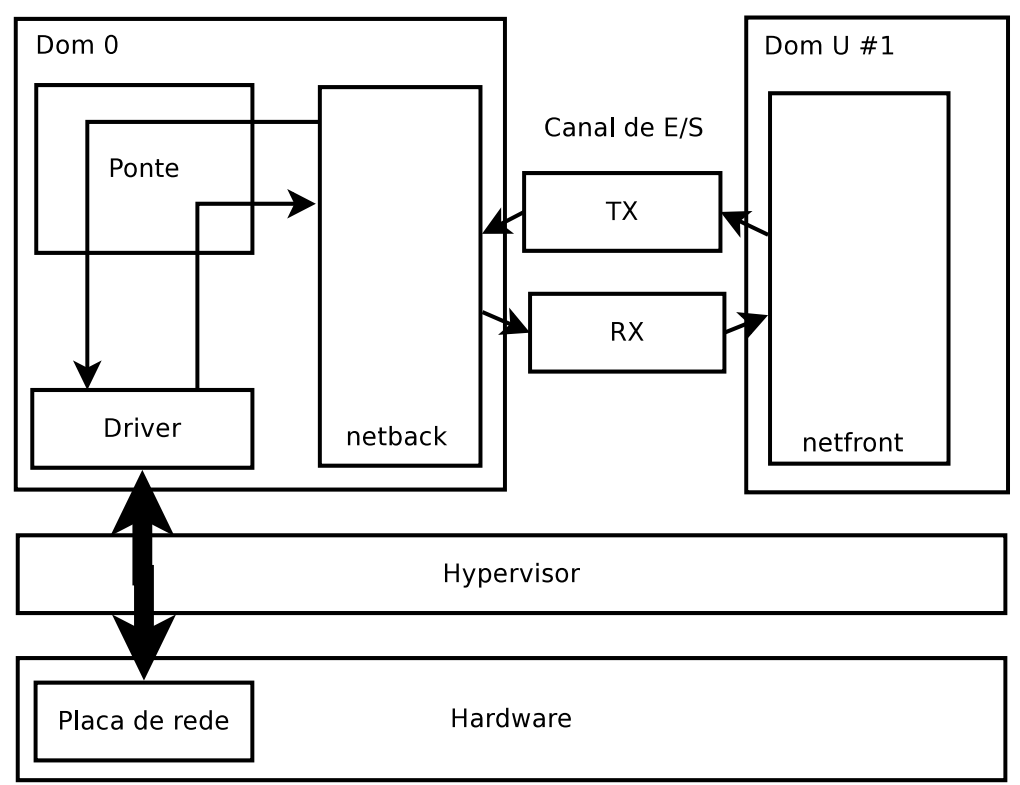

Figura 2.6: Arquitetura da rede virtual no Xen (simplificada e traduzida de [STJP08])

\subsection{Interrupções de Hardware X Interrupções de Software}

Interrupção é um sinal para o processador avisando que um evento precisa de imediata atenção. São normalmente usadas para tarefas de urgência ou de tempo-real e o sistema operacional deverá tratá-las o mais rápido possível. As interrupções de hardware são, como o próprio nome diz, interrupções geradas por dispositivos externos como o disco rígido, a placa de rede, mouse entre vários outros. Essas interrupções são usadas quando a estratégia para operações de E/S é a interrupção dirigida a $\mathrm{E} / \mathrm{S}$ ou $D M A$. Quando geradas, devem ser tratadas pelo núcleo do sistema o mais rápido possível, ignorando interrupções durante o processo e sem ceder o tempo para outros processos. Ou seja, o tratamento das interrupções de hardware é não preemptivo e não reentrante. Nesse caso, se o tratamento for demorado, outros processos terão um atraso de execução por falta de espaço de tempo no processador. Já se o tratamento da interrupção entrar em um laço infinito, o sistema entrará em livelock, ou seja, o sistema não estará bloqueado, porém, não será capaz de prosseguir porque todo o processador estará sendo usado para o tratamento da interrupção [SEB05].

Como cada dispositivo transfere informações em taxas diferentes, alguns geram mais interrupções que outros. As placas de rede que operam no padrão 10 Gigabit Ethernet por exemplo transferem dados com um taxa 3x maior que discos rígidos que operam no padrão SATA II como é possível ver na Figura 2.7 [Sta10].

Já as interrupções de software são semelhantes às interrupções de hardware, porém, são geradas por software. Assim, qualquer software no espaço do núcleo do sistema é capaz de gerar interrupções de software. Elas são reentrantes, mas não são preemptivas, ou seja não podem ser interrompidas tanto por interrupções de software como de hardware, porém, podem ceder seu tempo para outros processos tornando-as mais flexíveis em relação ao tempo gasto no tratamento delas [Cor12]. O uso delas é, normalmente, reservado para processos do sistema que exigem tempo real e que são importantes.

No sistema operacional GNU/Linux, o ksoftirqd é um processo do núcleo do sistema que ajuda no processamento das interrupções de software. Quando muitas interrupções de software são geradas, o sistema pode sobrecarregar. Nessa situação, o ksoftirqd passa a processar essas interrupções, e a controlar a reativação delas. Caso algum núcleo do processador esteja desocupado, o ksoftirqd é rapidamente escalonado. Já se não existir núcleo livre, é possível que o próprio ksoftirqd consuma toda $C P U$, então o sistema decide se valeria a pena escaloná-lo. 


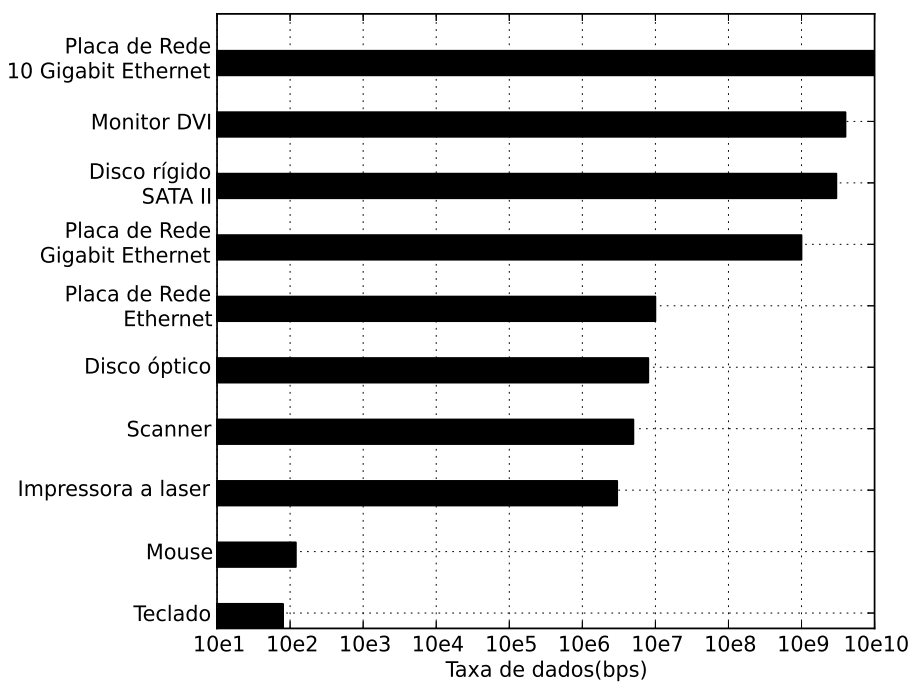

Figura 2.7: Taxa de transferência para diferentes dispositivos de E/S (traduzida e adaptada de [Sta10])

\subsection{Agregação de Interrupções}

Quando o tráfego de pacotes possui uma taxa de transmissão da ordem de Gbps no meio físico, a quantidade de interrupções devido a chegada de pacotes é muito grande podendo sobrecarregar o processamento [DXZL11]. Isso ocorre porque as interrupções têm prioridade absoluta sobre todas as outras tarefas e se a taxa de interrupções é suficientemente elevada, o sistema gastará todo seu tempo para respondê-las e o rendimento do sistema cairá para zero [Sal07].

A agregação de interrupções por intervalo de tempo ou número de pacotes é uma proposta da literatura para resolver esse problema [Sal07]. Ela pode ser implementada no driver do dispositivo e usada através do programa ethtool no sistema operacional GNU/Linux. O mecanismo de agregação de interrupções reduz a quantidade de interrupções na transmissão/recepção de pacotes dentro de um intervalo de tempo ou número de pacotes causando aumento na latência da rede. Existem 4 parâmetros para configuração da agregação de interrupções: tx-frames, rx-frames, tx-usecs e rx-usecs. A descrição de cada parâmetro está na Tabela 2.1.

Tabela 2.1: Parâmetros para agregação de interrupções

\begin{tabular}{|l|l|} 
nome & descrição \\
\hline tx-frame N & $\begin{array}{l}\text { gera uma interrupção quando a quantidade de pacotes } \\
\text { transmitida chegar a N } \\
\text { gera uma interrupção quando a quantidade de pacotes } \\
\text { dentro do buffer de recepção chegar a N } \\
\text { gera uma interrupção N microssegundos depois que um } \\
\text { pacote for transmitido } \\
\text { gera uma interrupção N microssegundos depois que um } \\
\text { pacote for recebido }\end{array}$ \\
rx-usecs N &
\end{tabular}

Como pode-se notar na Tabela 2.1, a agregação de interrupções depende do tamanho do buffer de transmissão e recepção. O buffer pode ser tanto um espaço de memória da máquina (DMA) como uma memória interna da placa de rede. Caso este seja pequeno, vários pacotes serão descartados durante o tráfego de pacotes por falta de espaço, caso seja grande, pode aumentar a latência por 
ter muitos pacotes esperando serem lidos dentro dele e pode consumir muita memória do sistema. Um problema com essa proposta é que nem sempre a placa de rede virtual ou física implementa essa funcionalidade, como o driver e1000 da Intel, o dispositivo de rede do Xen e o Virtio, que são mais usados pelos hypervisors.

\subsubsection{NAPI}

A NAPI (New API) [CRKH05] é um conjunto de interfaces oferecido pelo núcleo do Linux implementado pelos drivers dos dispositivos de rede para agregar interrupções. O objetivo dela é reduzir a carga extra do processamento na recepção de uma grande quantidade de pacotes em um ou mais dispositivos de rede. Para isso, no momento que uma grande quantidade de pacotes for enviada para o dispositivo de rede, ao invés do dispositivo enviar uma interrupção de hardware ao driver para cada pacote que chega, o driver desabilita a interrupção na chegada do primeiro pacote e processa continuamente os próximos pacotes numa estratégia de varredura como é mostrado na Figura 2.8.

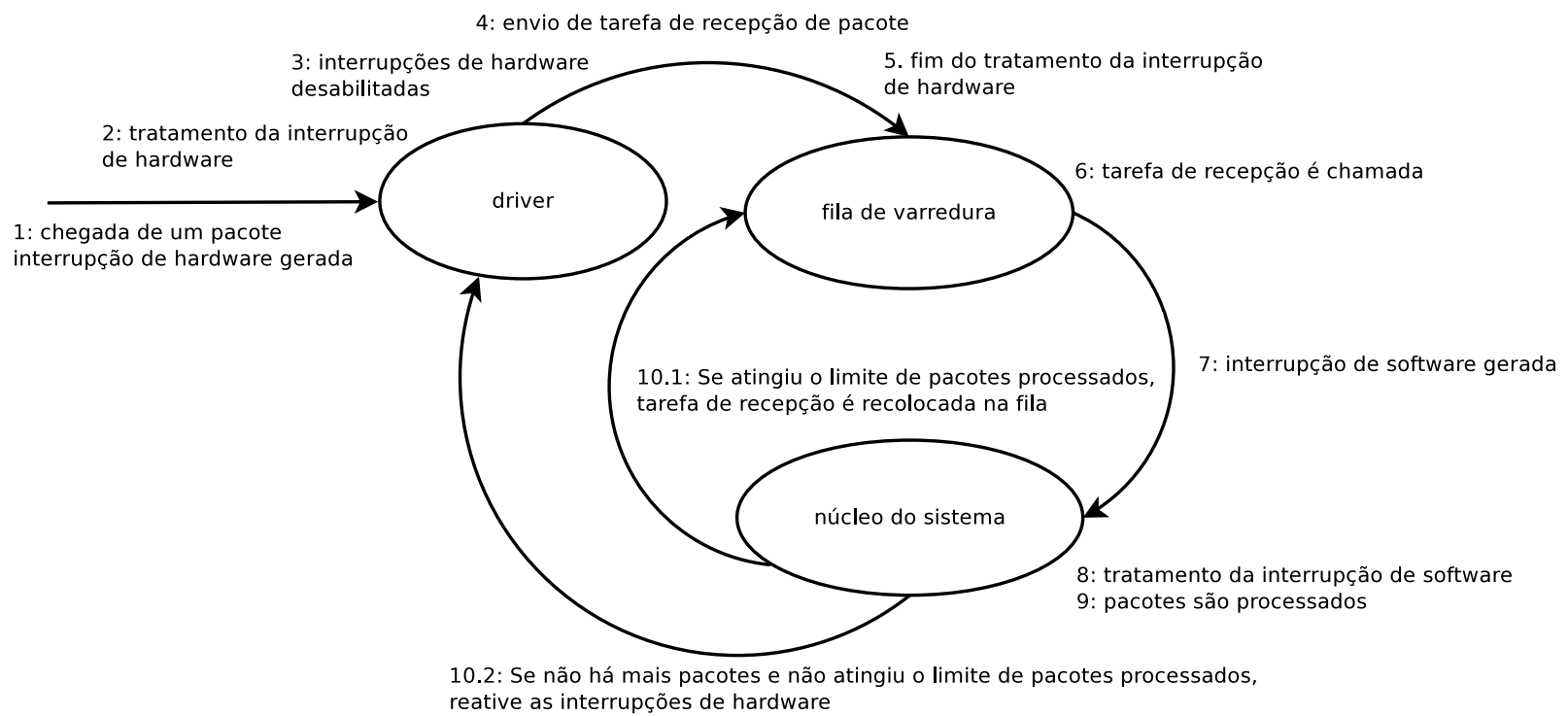

Figura 2.8: Fluxograma do funcionamento da NAPI

- Em 1, o driver recebe uma interrupção de hardware gerada pelo dispositivo de rede avisando sobre a chegada de um pacote.

- Em 2,3,4 o driver inicia o tratamento da interrupção de hardware, são desabilitadas as interrupções de hardware geradas pelo dispositivo de rede e, por fim, é enviada uma tarefa de recepção de pacotes na fila de varredura do núcleo do sistema.

- Em 5, o driver então termina o tratamento da interrupção de hardware.

- Em 6, a fila de varredura chama a tarefa de recepção de pacotes. Nessa tarefa, o sistema recebe os pacotes em nível de enlace e os encaminha para serem tratadas no nível de camada de redes.

- Em 7, uma interrupção de software é gerada pela fila de varredura para o núcleo do sistema.

- Em 8 e 9, o núcleo trata essa interrupção processando os pacotes que chegaram. Nota-se que pacotes podem chegar a qualquer momento e como as interrupções de hardware foram desabilitadas, os pacotes que chegam não geram interrupções de hardware. 
- Em 10.1 e 10.2, o núcleo verifica se a quantidade de pacotes processados atingiu um valor limite definido por parâmetro ou se não há mais pacotes para serem processados. Se atingiu o limite, a tarefa de recepção de pacotes é enviada de volta a fila de varredura. Já se não atingiu, as interrupções são reabilitadas e será necessário gerar uma outra interrupção de hardware para iniciar a recepção de pacotes. Quando uma grande quantidade de pacotes são enviadas para o sistema, a NAPI pode processar continuamente os pacotes reenviando a tarefa de recepção de pacotes para a fila de varredura. Esse processo forma um ciclo de varredura.

Comparando o uso da NAPI com a estratégia comum de interrupção dirigida a E/S, DMA e a estratégia de agregação de interrupções por intervalo de tempo e por pacote, notamos prós e contras.

Prós do uso da NAPI:

- A quantidade reduzida de interrupções de hardware geradas pelo dispositivo, já que a interrupção é desabilitada durante o processamento de pacotes;

- O processador fica menos ocupado tratando uma interrupção de hardware e, assim, reduz a chance do sistema entrar em livelock; Nesse caso é possível ainda, devido as interrupções de software, sobrecarregar a $C P U$, porém, o núcleo do sistema é capaz de controlar o tratamento delas através do ksoftirqd;

- Simplicidade, diferente da estratégia de agregação por intervalo de tempo e pacotes que necessita de ajustes manuais na configuração de acordo com o tipo de tráfego, a NAPI se ajusta ao tráfego, agregando mais interrupções quanto maior o tráfego de pacotes;

- A maioria dos drivers de dispositivos de rede virtuais atuais implementam NAPI. Por exemplo o Virtio, o driver do Xen e o e1000 da Intel.

Contras:

- Existe uma carga adicional com NAPI, já que não é gerada apenas uma interrupção de hardware, como também é gerada uma interrupção de software;

- O driver precisa implementar NAPI.

\subsection{Agregação de Interrupções na Transmissão x Recepção}

Tanto a transmissão quanto a recepção de pacotes podem gerar interrupções com uma frequência grande [MCZ06]. A transmissão gera uma interrupção quando um pacote é transmitido com sucesso e a recepção gera uma interrupção quando um pacote é recebido [CRKH05]. A diferença entre elas é que enquanto a transmissão pode controlar os pacotes que são enviados pelo sistema, a recepção não consegue controlar os pacotes que chegam. Assim, na transmissão pode-se reduzir de outras formas a quantidade de interrupções. Uma das principais propostas da literatura é o GSO (do inglês Generic Segmentation Offload) [Cor09]. O GSO permite ao driver de rede segmentar os pacotes, uma tarefa que normalmente é feita pelo processador.

Atualmente, o tamanho do pacote é limitado pela $M T U$ (do inglês Maximum Transmission Unit - Unidade Máxima de Transmissão). No protocolo Ethernet ela tem como valor padrão 1500 bytes. Esse valor acabou sendo adotado na época do crescimento da Internet pelos limites de hardware da época e infelizmente continua até hoje. Assim, não é possível enviar pacotes maiores que 1500 bytes pela Internet, o que força o sistema operacional a segmentar seus dados em pacotes pequenos para conseguir enviá-los. Isso sobrecarrega o processador tanto para segmentar os dados, como para enviar e receber esses pacotes. Nota-se que em uma rede local é possível configurar a $M T U$ de todos dispositivos e trabalhar com pacotes maiores, mas é restrito à rede local.

Com a segmentação sendo feita apenas no momento da transmissão dos pacotes pelo $G S O$, podese configurar o $M T U$ da interface de rede do sistema acima do limite do dispositivo físico. Com um 
$M T U$ maior, o pacote é segmentado em pedaços grandes e em menor quantidade quando o sistema manda transmiti-lo. Com menos pacotes, a quantidade de interrupções por pacote é reduzida. Na recepção, o LRO (do inglês Large Receive Offload) e o GRO (do inglês Generic Receive Offload) [Cor09] são soluções baseadas no GSO, onde os pacotes são montados quando recebidos. O LRO monta cada pacote agregando os pacotes TCP que chegam, porém, se por exemplo, existir uma diferença nos cabeçalhos do pacote $T C P$, haverá perdas na montagem, pois o pacote será montado sem considerar essa diferença. Já o GRO, restringe a montagem dos pacotes pelos cabeçalhos, o que não gera perdas e, além disso, o GRO não é limitado ao protocolo TCP. Apesar da proposta permitir a montagem de pacotes, como já foi dito, não é possível controlar a chegada de pacotes, o que força a adoção de alguma técnica de agregação de interrupções como a NAPI para conseguir montar os pacotes.

Todas as otimizações dessa seção já foram implementadas nos drivers atuais. É possível configurálas diretamente no código-fonte do driver ou pela ferramenta ethtool do Linux. 


\section{Capítulo 3}

\section{Revisão Bibliográfica}

O objetivo da revisão bibliográfica apresentada neste capítulo é analisar e estudar os problemas existentes na área de virtualização de dispositivos de rede. Também foram estudadas as estratégias de agregar interrupções tanto em dispositivos de redes virtuais como físicas. Nessa revisão, resumimos em poucos parágrafos os trabalhos de menor relevância na pesquisa e dedicamos uma subseção para cada trabalho de grande relevância.

\subsection{Resumo Sintetizado}

No trabalho de Walters, Chaudhary, Cha, Jr. e Gallo [WCC ${ }^{+} 08$ ], foi feita uma comparação entre o Xen, VMware e OpenVZ com relação ao desempenho da virtualização da rede. A partir dos experimentos foi concluído que o Xen apresenta alta latência, porém a capacidade de transferência de dados alcançada foi alta quando comparado com o OpenVZ e com um ambiente sem virtualização. O OpenVZ alcança menor capacidade de transferência de dados mas a latência é baixa. Quanto ao VMware, ele teve um desempenho baixo tanto em atraso quanto em capacidade de transferência de dados, ou seja, ele apresentou latência alta e baixa capacidade de transferência de dados. Os autores não entram em detalhes sobre os motivos dos resultados terem sido esses.

O trabalho de Ekanayake e Fox apresentado em [EF10] estudou a relação entre o número de núcleos, o número de máquinas virtuais e o desempenho da virtualização de rede usando Xen e Eucalyptus como infraestrutura de nuvem. O Eucalyptus é um software livre e de código aberto para construção de ambientes de computação em nuvem híbrida e privada. Foi concluído que a virtualização funciona bem para aplicações que não se comunicam muito, enquanto que em aplicações que são sensíveis a latência, houve perda de desempenho em relação a um ambiente não virtualizado. Outra conclusão foi que quanto maior o número de máquinas virtuais, maior a sobrecarga na $C P U$. A explicação para isso, segundo o autor, está na forma como é implementada a virtualização da rede. O hardware físico só pode ser controlado por um sistema (dom0), enquanto que os outros (domUs) para conseguirem fazer alguma operação de E/S pela rede, devem passar por esse sistema através de um canal. Isso transforma o dom0 em um gargalo do sistema.

No trabalho de Rixner [Rix08], foi feita uma revisão sobre a virtualização de rede. No texto o autor cita que a virtualização de rede impacta diretamente no número de servidores que podem ser diretamente consolidados dentro de uma única máquina física. Porém, as técnicas modernas de virtualização têm gargalos significantes, o que limita o desempenho da rede virtual. Ele comenta que há ganhos de desempenho caso o dispositivo utilizasse $D M A$. Entretanto, com $D M A$ um dispositivo poderia escrever em uma posição da memória que não pertence à máquina virtual que controla ele, podendo assim, causar problemas em outros processos da máquina física. Por conta da necessidade de acesso direto à memória e por causa dos problemas de segurança que apareceriam caso o DMA fosse utilizado, foi criada a unidade de gerenciamento de $\mathrm{E} / \mathrm{S}$ da memória (IOMMU - input/output memory management unit). Na IOMMU, a memória é restrita para o dispositivo de acordo com a 
máquina virtual que controla esse dispositivo. Atualmente os hypervisors modernos, como o Xen, dão suporte à $I O M M U\left[\mathrm{BDF}^{+} 03\right]$.

Como atualmente um processador possui vários núcleos, pode-se aproveitar esses núcleos para criar multi-filas nas interfaces de rede. Rixner cita que pesquisadores do laboratório da HP e Citrix eliminaram a ponte no domínio de $\mathrm{E} / \mathrm{S}$ para associar as máquinas virtuais diretamente com o driver de backend através das multi-filas, evitando a necessidade de sincronização das mensagens e multiplexação/demultiplexação da rede. Como benefícios do uso da multi-fila se teve: a redução da carga extra na fila e a eliminação de cópias entre o domínio de E/S e a máquina virtual, pois, a multiplexação não é feita. Por outro lado, é necessário que cada informação seja enviada para a fila correta e que a $C P U$ consiga lidar com a carga extra gerada pelas múltiplas filas.

Ainda no mesmo trabalho, Rixter comenta que na arquitetura de virtualização de rede CDNA (do inglês Concurrent Direct Network Access - Acesso Direto a Redes Concorrentes) foi empregada a proposta de multi-filas. Em adição foi removido o domínio de E/S. Sem o responsável por controlar as filas, o hypervisor passa a considerar cada conjunto de fila como uma interface de rede física e associa o controlador a uma máquina virtual. Assim, cada máquina virtual consegue enviar ou receber informações diretamente da rede sem nenhuma intervenção do domínio de $\mathrm{E} / \mathrm{S}$. Como consequência, a carga extra é menor pelo número reduzido de interrupções (antes era necessário interromper tanto o domínio de $\mathrm{E} / \mathrm{S}$ como as máquinas virtuais em cada transmissão/recepção). Entretanto, pelo fato da máquina virtual poder acessar diretamente a interface de rede, ela também pode acessar algum local indevido da memória por DMA. Para contornar esse problema o autor sugeriu o uso de IOMMU.

No trabalho de Waldspurger e Rosenblum [WR12], são citados diversos desafios e problemas na área de virtualização de E/S: a carga extra no hypervisor, a complexidade em gerenciar recursos (escalonamento e prioridades) e a dificuldade em fornecer uma semântica ao hardware virtual.

No trabalho de Liu [Liu10], foram executados diversos experimentos com virtualização de E/S baseada em software usando Virtio e em hardware usando SR-IOV (do inglês Single Root I/O Virtualization - Virtualização de E/S de Raiz Única) com o hypervisor KVM. O Virtio é um padrão do Linux para drivers de rede e disco que rodem em um ambiente virtual cooperado com um hypervisor para-virtualizado. Ele tem um padrão arquitetural similar aos drivers de rede do Xen. Já o SR-IOV é uma especificação que permite a dispositivos pci-express fornecerem interfaces extras com funcionalidades reduzidas para serem usadas pelas máquinas virtuais diretamente.

Foram analisadas as seguintes métricas nos experimentos: a capacidade de transferência de dados via rede, a latência e o uso do processador. Em termos de latência, o Virtio teve um desempenho muito baixo. A explicação, provada desabilitando a função de agregação de interrupções na transmissão, é que o hospedeiro atrasa o envio do pacotes para que eles sejam enviados em rajadas, mas mesmo assim, a latência com a agregação de interrupções desligada foi aproximadamente 20 microssegundos maior do que a latência na máquina não virtualizada. Conforme explicado na Seção 2.6, quando a opção de agregação é desabilitada, há uma perda de desempenho, pois cada pacote que é transmitido gera uma carga de trabalho na $C P U$. Com a mitigação a carga por pacote é reduzida. Já o SR-IOV teve um desempenho próximo da máquina física (ou pura), com um aumento de poucos microssegundos devido à virtualização da interrupção.

Em termos de capacidade de transferência de dados via rede, todas as configurações tiveram o mesmo desempenho ao transmitir pacotes. Por outro lado, na recepção, o SR-IOV se aproximou da máquina pura, mas o uso da sua $C P U$ foi muito maior que as demais. No Virtio, ele não conseguiu um bom desempenho, mas o uso de sua $C P U$ foi baixo. No experimento de uso da memória na recepção, o SR-IOV teve um uso muito menor que o Virtio, assim, o autor concluiu que o baixo desempenho na recepção de pacotes com o Virtio foi pelo uso excessivo da memória, o que explica também o baixo uso da $C P U$.

No trabalho de Santos, Turner, Janakiraman e Pratt [STJP08], foi apresentada uma proposta 
para modificar a arquitetura do driver de $\mathrm{E} / \mathrm{S}$ do Xen com o objetivo de otimizar o uso da $C P U$. Dentro dos problemas que o autor encontrou na arquitetura padrão do Xen está o excesso de cópias de dados. Para reduzir o excesso de cópias, foram propostas otimizações nas operações de remapeamento de páginas tanto na transmissão como na recepção de pacotes. As modificações realizadas levaram a reduções de até $56 \%$ no uso do processador.

No trabalho de Oi e Nakajima [ON09], foi analisado o desempenho de um sistema virtualizado com Xen aplicando a estratégia LRO. Nesse experimento foram medidos a vazão da rede variando o tamanho da mensagem e o tamanho da $M T U$. Os resultados mostraram um ganho de $8 \%$ a $14 \%$ na vazão da rede.

No trabalho de Apparao, Makineni e Newell [AMN06], foram pesquisadas as principais causas de carga extra na virtualização de E/S. Nos experimentos realizados eles avaliaram duas configurações de virtualização de E/S: o domU e o domo alocados na mesma $C P U$ e em $C P U s$ distintas. O resultado mostrou que nos dois métodos, tanto a transmissão como a recepção de pacotes apresentaram uma perda de desempenho de mais de $50 \%$ quando comparado com a máquina física. Também foi observado que executar o domu e o dom0 em CPUs distintas é mais custoso que executar elas na mesma $C P U$.

No trabalho de Jang, Seo, Jo e Kim [JSJK11], foi verificado se há vantagens em sacrificar o isolamento que existe entre as máquinas virtuais quando o objetivo é reduzir a carga extra sobre o processador. Os resultados mostraram uma redução de $29 \%$ no uso do processador e $8 \%$ de ganho na capacidade de transferência de pacotes grandes.

No trabalho de Fortuna e Adamczyk [FA12], foram feitos experimentos com o objetivo de avaliar o problema da carga extra na virtualização da rede. Para isso, os autores propuseram adequar o balanceamento de interrupções para demonstrar a possibilidade de reduzir o número de pacotes perdidos. No balanceamento de interrupções, é feita a associação da interrupção com uma determinada $C P U$. O resultado foi que um balanceamento adequado pode melhorar muito o desempenho, porém, o comportamento é difícil de ser previsto, dificultando a elaboração de um algoritmo. Uma proposta futura sugerida foi deixar o núcleo do sistema automatizar o processo de balanceamento e analisar os resultados. Eles também discutiram a possibilidade de usar a função de agregação existente nos drivers das placas de rede modernas para um trabalho futuro.

\section{Evaluating System Performance in Gigabit Networks [SEB05]}

No trabalho de Salah e El-Badawi [SEB05], é feita uma análise e simulação sobre o impacto da sobrecarga de interrupções no desempenho do sistema operacional em redes de alta velocidade. $\mathrm{O}$ principal problema que eles exploraram é a grande quantidade de interrupções gerada na recepção de pacotes. Como a interrupção tem prioridade máxima em relação a outras tarefas, quando em excesso ela acaba consumindo todo tempo de processamento, impedindo outras tarefas de serem realizadas e, consequentemente, reduzindo a taxa de transferência do sistema a 0. Essa situação é conhecida como "livelock".

Para analisar a situação de sobrecarga de interrupções, os autores modelaram o sistema como uma fila $\mathrm{M} / \mathrm{M} / 1 / \mathrm{B}$ com chegada de pacotes seguindo uma distribuição de Poisson de taxa $\lambda$ e média efetiva de tempo de serviço de $1 / \mu$. O sistema pode usar ou não $D M A$. Sem $D M A$, o processador gerencia a recepção de pacotes. Quando o processador é interrompido enquanto está processando um pacote pela chegada de um outro pacote, o tempo para processar é estendido para realizar uma cópia individual do outro pacote que chegou para a memória do sistema. Com DMA, a placa de rede tem acesso direto a memória. Quando um ou mais pacotes chegam enquanto o sistema ainda está processando um outro pacote, todos são processados sem estender o tempo de processamento.

Foram feitos experimentos analisando o sistema ideal, DMA habilitado e DMA desabilitado. Com 
pouco tráfego de pacotes, a taxa de transferência de todos foi a mesma. Já com muito tráfego, a taxa de transferência do sistema com o $D M A$ habilitado teve uma queda menor na taxa de transferência do que o sistema sem o DMA habilitado. O sistema ideal apresentou taxa de transferência constante.

\section{To Coalesce or Not To Coalesce [Sal07]}

No trabalho de Salah [Sal07], que é uma continuação do trabalho anterior [SEB05], é analisado o desempenho de duas técnicas de agregação de interrupções: baseada em contagem e baseada em tempo. Na técnica baseada em tempo, o driver da placa de rede não gera interrupções no sistema quando um pacote é recebido. Ao invés disso, uma interrupção é gerada depois de um certo intervalo de tempo que um pacote é recebido. Já na técnica baseada em contagem, é gerada uma interrupção quando uma certa quantidade de pacotes é recebida.

A conclusão tirada a partir dos modelos analíticos é que a agregação funciona melhor que o modelo de interrupção comum quando se tem um grande tráfego na rede. Porém, quando há pouco tráfego na rede, a interrupção comum superou a agregação. Os autores sugerem monitorar o tráfego e fazer a troca entre a interrupção comum e a agregação de interrupções a depender da taxa de transferência de dados. Eles também citam um momento que pode ser usado para indicar a condição de sobrecarga. Este momento pode ser usado para a troca. Outras importantes conclusões são (1) que na agregação são necessários valores altos de parâmetros em tráfegos intensivos; (2) que para tráfegos tolerantes a latência, o uso de agregação é interessante independente do tráfego e (3) que para tráfegos de tempo não-real é interessante usar a agregação baseada em tempo ao invés da baseada em contagem por impor um limite de atraso na agregação.

No artigo de Salah e Qahtan [SQ09], foi apresentada uma estratégia de recepção de pacotes chamada ativação-desativação de interrupções e implementada uma estratégia híbrida de recepção no driver de dispositivo de rede. A ativação-desativação de interrupções funciona como a estratégia comum de gerar uma interrupção a cada pacote que chega, porém, durante a recepção do pacote, as interrupções de recepção são desabilitadas impedindo os pacotes que chegam durante o processo de recepção de gerarem interrupções desnecessárias. A estratégia híbrida alterna entre a NAPI e a ativação-desativação de interrupções dependendo do tráfego. Em tráfegos moderados, o driver recebe pacotes ativando-desativando interrupções. Já em tráfegos intensivos o driver passa a usar NAPI. Nos experimentos, foram comparadas as estratégias de ativação-desativação de interrupções, $N A P I$ e a proposta de estratégia híbrida. A estratégia híbrida teve um desempenho melhor que a NAPI tanto para tráfegos intensivos como moderados, mas isso foi devido ao parâmetro limite da NAPI que foi configurado diferente nas duas estratégias.

\section{Interrupt Moderation Using Intel GbE Controllers [Int07]}

No trabalho da Intel [Int07], é citado o problema da grande quantidade de interrupções geradas na transmissão e recepção de pacotes. Para resolvê-lo, os autores propuseram o uso de temporizadores internos na placa de rede para moderar a quantidade de interrupções geradas. Os temporizadores são divididos em temporizador absoluto, pacote e mestre. O temporizador absoluto inicia uma contagem regressiva quando o primeiro pacote chega ou é enviado. No momento que a contagem chega a zero, é gerada uma interrupção no sistema. Este temporizador é eficiente quando se tem muito tráfego de pacotes, pois muitos pacotes chegam/são enviados até o temporizador gerar a interrupção, reduzindo a quantidade de interrupções por pacote. Por outro lado, ele não é eficiente quando há pouco tráfego porque poucos pacotes chegam/são enviados até o temporizador gerar a interrupção o que acaba atrasando as interrupções e, consequentemente, o momento em que as informações chegam ao sistema.

O temporizador de pacotes também inicia uma contagem regressiva quando o primeiro pacote chega ou é enviado e também gera uma interrupção quando a contagem chega a zero, mas ele é reiniciado sempre que um novo pacote chega. Isso reduz a latência quando há pouco tráfego no enlace, pois a interrupção é gerada quando o temporizador percebe que nenhum pacote será mais enviado/recebido, mas quando há muito tráfego, ele pode nunca gerar a interrupção, pois o tempo- 
rizador estará sempre sendo reinicializado pelos pacotes que chegam/são enviados. O temporizador mestre é usado para otimizar os outros temporizadores. O temporizador absoluto e o temporizador de pacotes podem ser combinados para chegar a um bom resultado.

Além dos temporizadores já citados, existe um outro mecanismo chamado limitador de interrupções. Esse mecanismo também é um temporizador de contagem regressiva e limita o número de interrupções por segundo. Quando o temporizador inicia a contagem regressiva, este também começa a contar o número de interrupções que foram geradas. Quando a contagem chega a zero, o contador de interrupções também é zerado. Se o número de interrupções ultrapassar o limite estabelecido, as interrupções geradas são adiadas até o contador ser reinicializado.

Um algoritmo foi proposto para moderação de interrupções que ajusta dinamicamente o valor do limitador de interrupções. Dependendo do padrão de E/S, é usado um valor no limitador. O padrão de E/S é categorizado em: baixíssima latência, onde o tráfego é mínimo e predomina os pacotes pequenos, baixa latência, onde o tráfego também é minimo e há um significante percentual de pacotes pequenos, e intermediário, onde há muito tráfego de pacotes medianos. Em [Int07] os autores não explicam como chegaram nos valores usados no algoritmo e porque eles resolveram dividir o padrão de $\mathrm{E} / \mathrm{S}$ dessa forma.

\section{Placas de rede da Intel}

Atualmente, a Intel é uma empresa que tem investido em pesquisas de dispositivos de rede. Suas placas de rede implementam várias funcionalidades exclusivas como a interrupção de baixa latência e a moderação de interrupções [Int11]. A interrupção de baixa latência permite que seja gerada uma interrupção imediatamente após a recepção de um pacote que segue algum critério. Este critério pode ser o valor da porta de destino do pacote, o tamanho do pacote ou o tipo de protocolo.Apesar dessas funcionalidades ajudarem muito na pesquisa de agregação de interrupções, uma placa de rede da Intel com todas essas funcionalidades possui um custo muito alto, o que inviabiliza fazer experimentos com ela.

\section{Linux}

Linux é um clone do sistema operacional Unix escrito do zero por Linus Torvalds com ajuda de uma equipe de hackers espalhada por todo o mundo. Seu código-fonte pode ser obtido em http: //github.com/torvalds/linux. É importante destacar que tanto o código quanto a documentação são de alta qualidade e atualizados diariamente sendo uma importante fonte de informação confiável para pesquisas. Muitos detalhes e dúvidas tanto de implementação quanto para entender melhor o funcionamento do driver de rede foram esclarecidos quando navegamos pelo seu repositório.

Estudando o código-fonte dos drivers encontrados no repositório do Linux, percebemos que a grande maioria implementava NAPI por padrão. Outras estratégias para reduzir interrupções como a agregação por intervalo de tempo e por pacotes não foram implementadas.

\subsection{Resumo Conclusivo}

Nessa revisão, foram encontrados diversos artigos com propostas que modificam diferentes partes da infraestrutura: driver de rede, placa de rede física, arquitetura da virtualização da rede e núcleo do sistema operacional. No artigo da Intel [Int07], foi proposto um algoritmo para a moderação de interrupções de acordo com o padrão de E/S. Não ficou claro como os autores criaram o algoritmo, e para que ele funcione é necessário a funcionalidade de moderação de interrupção que apenas alguns drivers implementam. No segundo artigo de Salah [Sal07], foi criado um modelo analítico e um simulador para analisar a estratégia de agregação de interrupções por intervalo de tempo e por quantidade de pacotes. Porém, atualmente, não foi possível encontrar drivers que implementem essas funcionalidades. No terceiro artigo de Salah [SQ09], foi apresentada uma estratégia híbrida de interrupções em dispositivos físicos. Uma desvantagem dessa estratégia é a necessidade de definir o momento em que se deve trocar entre NAPI e ativação-desativação de interrupções. Experimentos 
com placas que implementam SR-IOV e placas da Intel apresentaram progressos na virtualização de rede, porém, são muito caras atualmente. A NAPI pareceu ser a estratégia mais utilizada atualmente pelos fabricantes de dispositivos de rede. Nesse estudos vimos que os drivers e1000, r8169, Virtio e tg3 implementavam NAPI. Não foram encontrado muitos artigos relacionados a esse tópico.

A revisão ajudou a entender melhor a área de virtualização de rede. Porém, foi notada também a falta de detalhes técnicos nos artigos, o que dificulta o entendimento deles. Outro problema é a rápida desatualização das pesquisas. O progresso tanto do Linux quanto dos drivers deixaram muitas propostas de agregação de interrupções obsoletas, como a agregação por intervalo de tempo e por pacotes. 


\section{Capítulo 4}

\section{Experimentos}

Para analisar o desempenho da NAPI em dispositivos de rede virtuais, foram realizados experimentos variando o parâmetro limite do driver de rede e1000 da Intel em vários hypervisors diferentes. Esse driver implementa NAPI e tem o código-fonte claro e bem escrito, sendo usado por vários hypervisors como Xen, VirtualBox, VMware e KVM para processar a recepção e transmissão de dados pela rede na máquina virtual. Outras soluções que os hypervisors teriam são os drivers de para-virtualização do Xen e do Virtio. Ambos têm um desempenho superior ao e1000 por usarem técnicas de para-virtualização, porém, são mais complexos porque se comunicam diretamente com a máquina física.

$\mathrm{Na}$ implementação de recepção de pacotes do e1000, o limite define a quantidade limite de pacotes que a tarefa de recepção poderá coletar por ciclo de varredura. Se a quantidade de pacotes atingir esse limite ou esgotar o tempo limite de espera de pacotes, a tarefa é recolocada na fila de varredura, caso contrário, é removida da fila. Sendo assim, valores pequenos de limite farão com que menos pacotes sejam coletados por ciclo de varredura, porém, mais vezes a tarefa de recepção é recolocada na fila de varredura. O objetivo dos experimentos neste capítulo é estudar o comportamento dos dispositivos de rede virtuais usando NAPI com diferentes tipos de hypervisors.

As próximas seções deste capítulo estão organizadas da seguinte forma: Na Seção 4.1 estudamos a taxa efetiva de transferência de dados da placa de rede em função do protocolo da camada de transporte e do valor configurado para o limite. Na seção 4.2, apresentamos os resultados obtidos com experimentos para avaliar o desempenho da placa de rede virtualizada com diferentes valores de limite, diferentes taxas de transmissão de dados e diferentes hypervisors em transferências de dados usando o protocolo UDP. Na seção 4.3, analisamos os resultados obtidos nos experimentos anteriores.

\subsection{Banda X Limite}

Neste primeiro experimento estudamos a taxa efetiva de transferência de dados da placa de rede em função do protocolo da camada de transporte e do valor configurado para o limite. Como hypervisor foi usado o VirtualBox. A máquina física contém um processador i7-2620M de dois núcleos e quatro fluxos de execução, 8 Gigabytes de memória $R A M$ e sistema operacional Mac $O S$ $X$ 10.6.8 enquanto que a máquina virtual usa dois fluxos de execução, 5 Gigabytes de memória RAM e sistema operacional Ubuntu 11.10 com núcleo Linux 3.0.43.

Foram analisadas a taxa de recepção de dados pelo software iperf, que é um software para testar o desempenho da largura de banda da rede, e a quantidade total de pacotes processada pelo driver. O limite teve os valores de 1 a 10 variando de um em um, de 10 a 100 variando de dez em dez e 200. A escolha do intervalo reduzido quanto menor o limite foi feita considerando que as interrupções de hardware reduzirão significantemente nos menores valores de limite e muito pouco nos maiores, sendo assim, é esperado que variações na taxa de recepção dos dados ocorram com valores de limite baixos (foram consideradas as conclusões dos trabalhos de Corbet [Cor05] e de Salah [SQ09], que sugerem um melhor desempenho para valores baixos de limite). A taxa de recepção dos dados foi 
medida usando o programa iperf com protocolo $T C P$ e $U D P$ durante 30 segundos e a quantidade de pacotes foi medida usando o programa ifconfig. A taxa de transmissão configurada no iperf foi a máxima que a máquina física conseguiu transmitir para a máquina virtual. Com o protocolo $T C P$ tal valor não é configurado pois depende do mecanismo de controle de fluxo. Com o protocolo $U D P$ configuramos para transmitir a $1 \mathrm{Gbit} / \mathrm{s}$, mas a transmissão alcançou no máximo $810 \mathrm{Mbits} / \mathrm{s}$.

Nos gráficos, são mostradas a média e intervalo de confiança de $95 \%$. Cada experimento foi repetido 10 vezes.

O gráfico da Figura 4.1 plota a taxa de recepção medida pelo iperf com o protocolo TCP. Percebe-se que com limites baixos, o desempenho da placa de rede é menor em relação aos experimentos com limites altos. No gráfico da Figura 4.2, é plotada a quantidade de pacotes recebidos pelo driver. Nota-se que existe uma semelhança grande entre os gráficos das figuras 4.1 e 4.2 . Uma correlação linear foi feita através do coeficiente de correlação de Pearson com as informações da taxa de recepção e da quantidade de pacotes recebidos. O resultado foi de 0,9999, uma forte correlação. Nesse caso, o tráfego de pacotes no nível de enlace e no nível de aplicação foram praticamente iguais não havendo perdas.

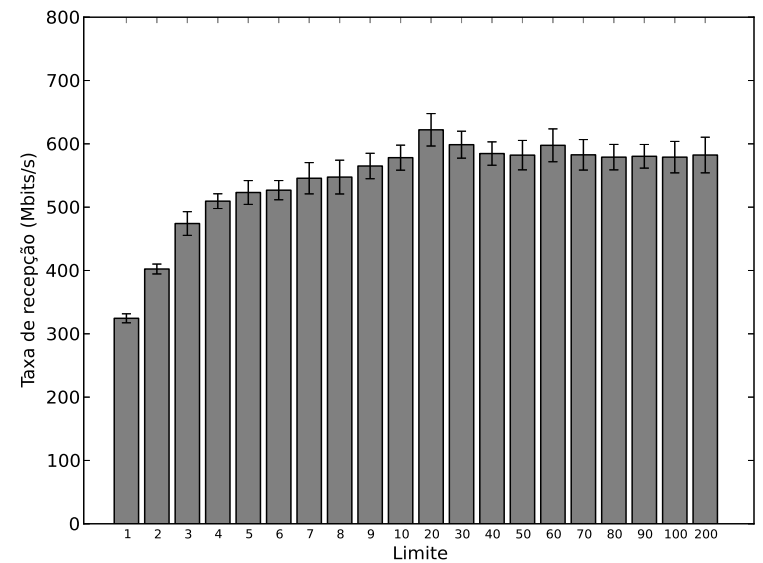

Figura 4.1: Taxa de recepção de pacotes com protocolo TCP

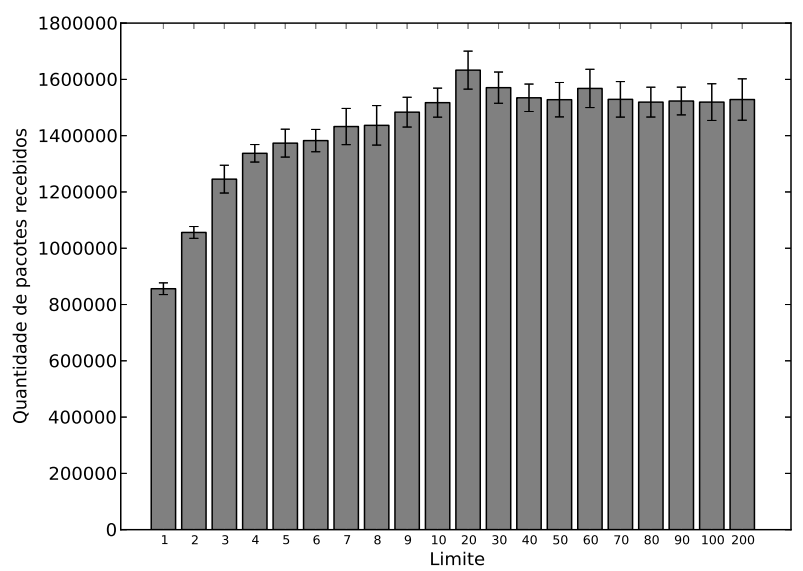

Figura 4.2: Quantidade de pacotes recebidos pelo driver com protocolo TCP

O gráfico da Figura 4.3 plota a taxa de recepção medida pelo iperf com o protocolo UDP. 
Percebe-se um comportamento diferente em relação ao TCP visto na Figura 4.1. Enquanto com $T C P$, o aumento no limite eleva a taxa de recepção, o contrário ocorre com $U D P$, o aumento do limite reduz a taxa de recepção. Nota-se também um resultado incomum, a taxa do UDP apresenta resultados muito inferiores em relação ao $T C P$.

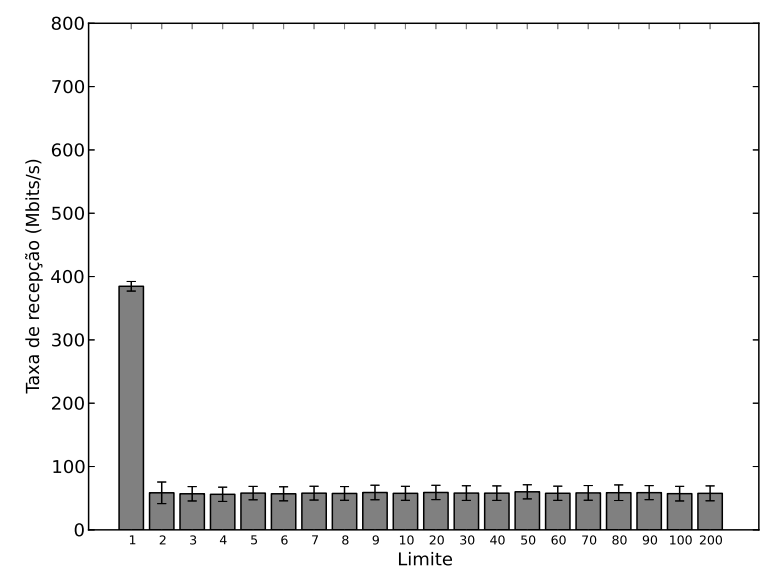

Figura 4.3: Taxa de recepção de pacotes com protocolo UDP

No gráfico da Figura 4.4, é plotada a quantidade de pacotes recebidos usando UDP. Nota-se que o gráfico se diferencia completamente em relação ao gráfico da Figura 4.3. A correlação linear entre os dois gráficos foi de -0,9999, um resultado contrário em relação ao experimento com $T C P$.

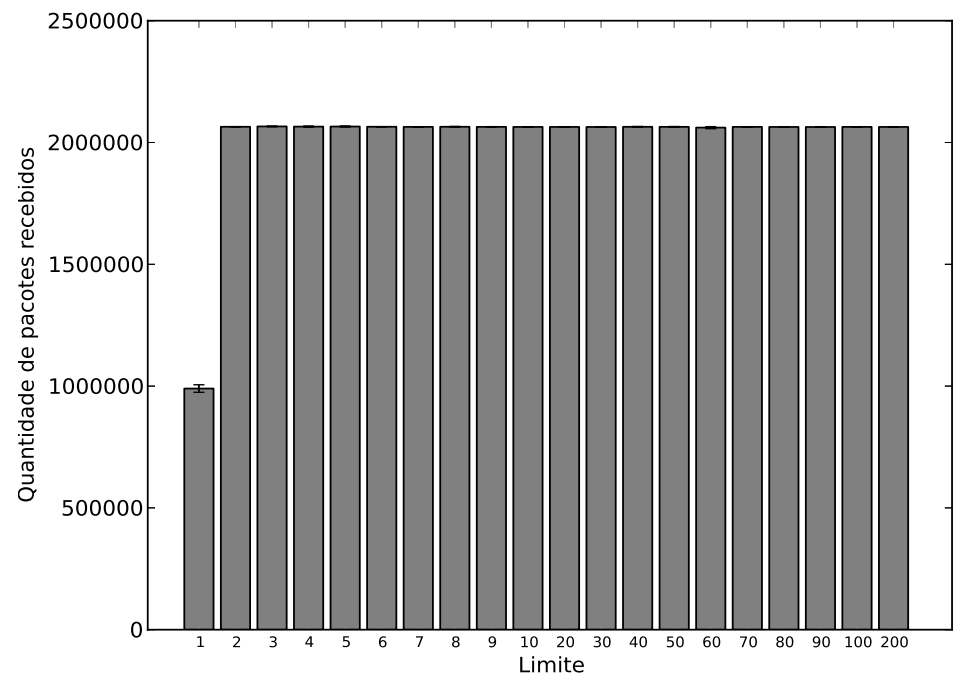

Figura 4.4: Quantidade de pacotes recebidos pelo driver com protocolo UDP

Existe uma possível resposta para esse resultado: no $U D P$, os pacotes são processados em grandes quantidades no driver, com exceção do experimento com limite igual a 1. Entre a passagem pelo driver até a chegada no iperf pode ocorrer um transbordamento em uma fila de pacotes devido ao excesso de pacotes, o que faz o iperf ter perdas refletindo assim na baixa taxa de recepção percebida pela máquina virtual. No $T C P$, devido a característica do protocolo de controlar o fluxo, o envio de pacotes é mais lento e o sistema não consegue transbordar a fila. 
Sendo mais específico, o transbordamento observado nos experimentos com UDP ocorreu no buffer de recepção do socket criado pelo iperf. Para comprovar essa hipótese aumentamos esse buffer modificando as variáveis de socket com o sysctl, que permite ler e modificar variáveis de sistema no Linux. Com esse aumento percebemos um aumento expressivo da taxa de recepção como é visto nas figuras 4.5 e 4.6. A correlação linear nesse caso foi de 0,9426. Talvez seja possível encontrar uma configuração de buffer que leve a uma maior correlação, mas o resultado observado pelos nossos experimentos já é suficiente para mostrar que limites altos levam a uma maior taxa de recepção de dados no $U D P$, mas apenas se configurarmos o buffer corretamente, em situações onde a taxa de transferência dos dados seja intensa.

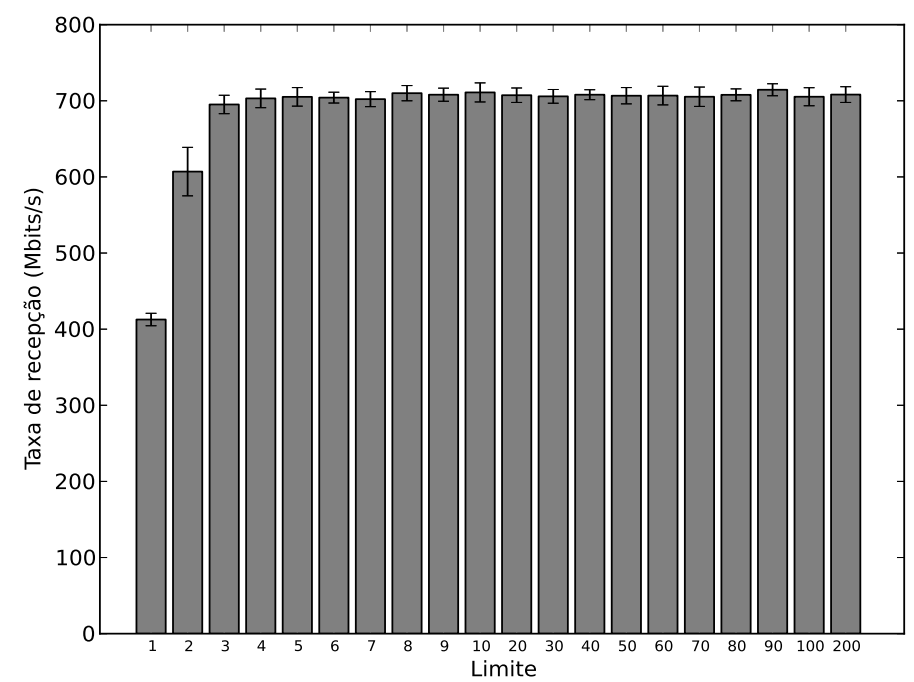

Figura 4.5: Taxa de recepção de pacotes com protocolo UDP modificando o buffer de recep̧c̃a

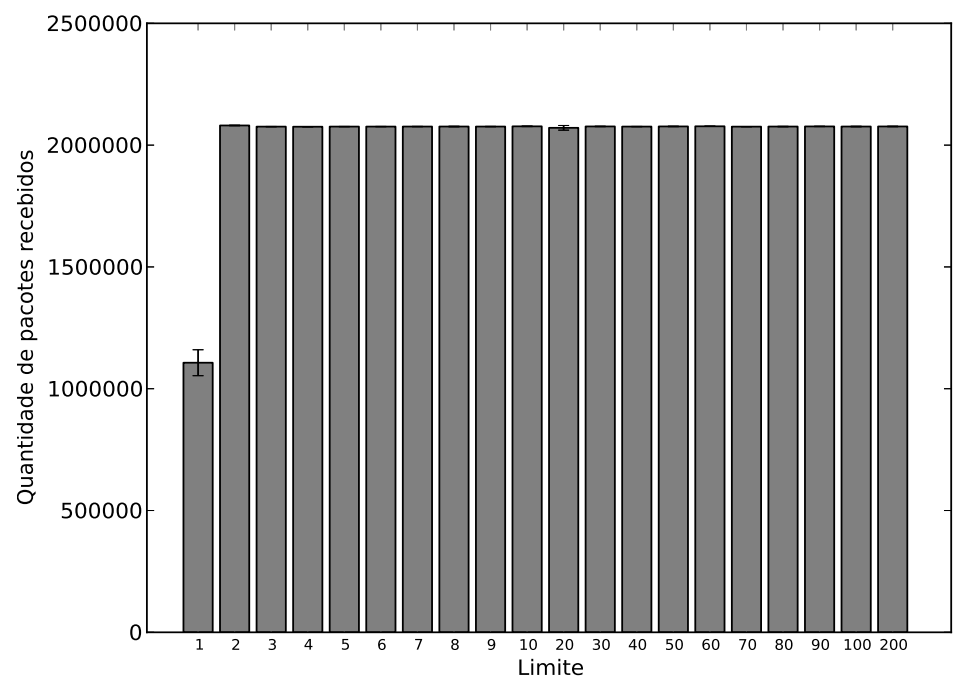

Figura 4.6: Quantidade de pacotes recebidos pelo driver com protocolo UDP modificando o buffer de recepção

Assim, concluímos tanto com TCP como com UDP que configurações de limite alto e ajustes no buffer resultam em uma taxa de recepção de dados maior que configurações com limites bai- 
xos e sem alterações no tamanho do buffer. No restante deste capítulo, será estudada a causa dos drivers apresentarem um melhor desempenho quando configurados com limites altos em relação a configurações com limites baixos. 


\subsection{Análise de Desempenho com Diferentes Hypervisors}

Esta seção apresenta os resultados obtidos com experimentos para avaliar o desempenho da placa de rede virtualizada com diferentes valores de limite, diferentes taxas de transmissão de dados e diferentes hypervisors em transferências de dados usando o protocolo UDP. Como hypervisor foram usados o VirtualBox, o VMware e o Xen com virtualização nativa.

No experimento com o VirtualBox e VMware foram usadas as mesmas configurações de hardware e sistema operacional que no experimento relatado na Seção 4.1. No Xen, a máquina física contém um processador i7 Ivy Bridge de quatro núcleos e oito fluxos de execução, 16 Gigabytes de memória $R A M$ e sistema operacional Ubuntu 12.10, enquanto que a máquina virtual usa dois fluxos de execução, 5 Gigabytes de memória $R A M$ e sistema operacional Ubuntu 11.10 com núcleo Linux 3.0.12. Apesar da diferença do núcleo Linux, as demais configurações da máquina virtual são as mesmas usadas nos experimentos com o VirtualBox e com o VMware.

Foram variados a taxa de transmissão de 100 até $1000 \mathrm{Mbits} / \mathrm{s}$ de cem em cem e o limite em 1, 2, 60 e 200 usando protocolo UDP. A escolha do UDP foi devido a possibilidade de controlar a taxa de transmissão e a pouca intervenção no fluxo de pacotes em relação ao TCP. O tamanho do buffer de recepção do socket foi configurado em 8 Mbytes para evitar os problemas observados nos experimentos resumidos nos gráficos das figuras 4.3 e 4.4. Foram medidos a taxa de recepção do iperf e a quantidade de pacotes recebidos usando o ifconfig. No iperf é analisado o tráfego de pacotes na camada de aplicação enquanto que no ifconfig é analisado na camada de enlace. Também foram analisados o uso de $C P U$ total e o uso de $C P U$ pelas interrupções de software usando o software sar, um software que informa as atividades do sistema. No uso de $C P U$, é considerando $100 \%$ o uso de uma linha inteira de execução, $200 \%$ duas linhas e assim por diante. Cada gráfico mostra a média dos resultados do experimento. Cada experimento foi repetido 5 vezes. A dispersão observada nas repetições foi pequena. Por isso, para não poluir os gráficos, os intervalos de confiança foram omitidos.

As subseções seguintes estão organizadas da seguinte forma: Na subseção 4.2.1, mostramos o resultado do primeiro experimento com o VirtualBox. Na subseção 4.2.2 refizemos o experimento do VirtualBox com afinidade de $C P U$. Nas subseções 4.2 .3 e 4.2 .4 mostramos o resultado dos experimentos com respectivamente o Xen e o VMware.

\subsubsection{VirtualBox}

\section{Recepção de Pacotes}

No gráfico da Figura 4.7 é plotada a taxa de recepção medida pelo iperf em relação a diferentes taxas de transmissão. Nota-se que para todos os limites há perdas de pacotes, já que a taxa de recepção medida é menor do que a taxa de transmissão, mas para valores maiores de taxa de transmissão, essa perda é reduzida.

Percebe-se também que com limite igual a 1, quando a taxa de transmissão é maior que 500 Mbits/s o sistema passa a processar aproximadamente $400 \mathrm{Mbits} / \mathrm{s}$. Com os resultados dos próximos experimentos será analisada a causa desse comportamento.

No gráfico da Figura 4.8 é mostrada a quantidade de pacotes recebidos pelo driver. Percebe-se que todas as curvas apresentam um comportamento crescente e num determinado momento, elas ficam constantes limitadas por algum fator.

A curva para o limite igual a 1 passa a ser constante quando a taxa de transmissão é maior que $500 \mathrm{Mbits} / \mathrm{s}$. Provavelmente, o sistema começou a descartar pacotes por perceber que não seria capaz de processá-los, uma característica da NAPI. Já as curvas para os outros limites passam a ficar constantes somente em $800 \mathrm{Mbits} / \mathrm{s}$ que é próximo do limite observado com o iperf. Isso significa que o driver conseguiu processar todos os pacotes e não houve perdas. Assim, novamente, entre o driver e a recepção de pacotes do iperf, alguns pacotes deixaram de ser processados para justificar o comportamento do gráfico da Figura 4.7. 


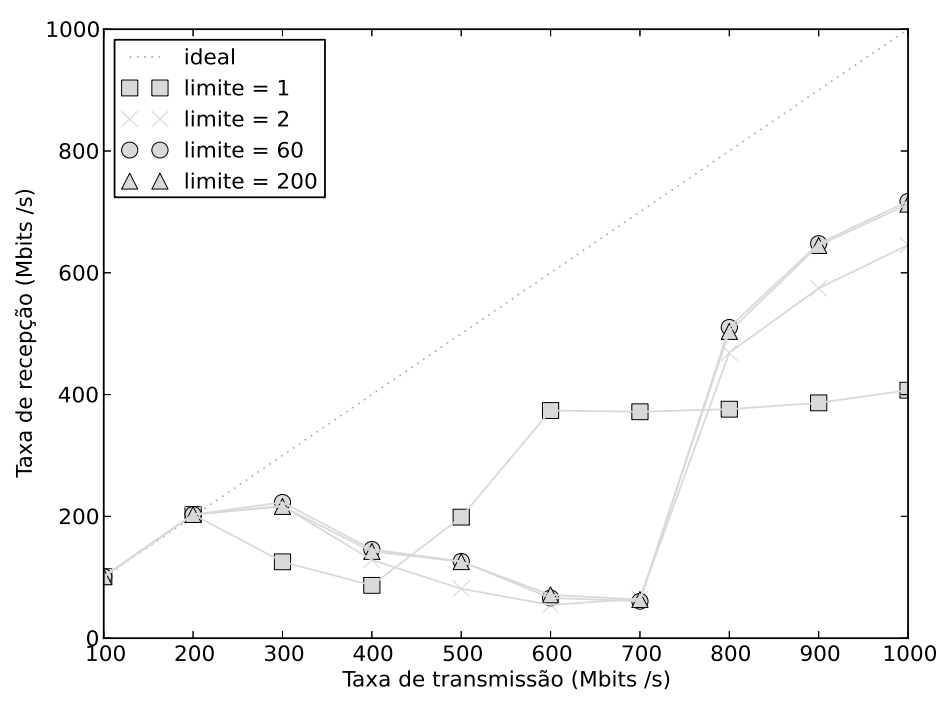

Figura 4.7: Taxa de recepção no VirtualBox

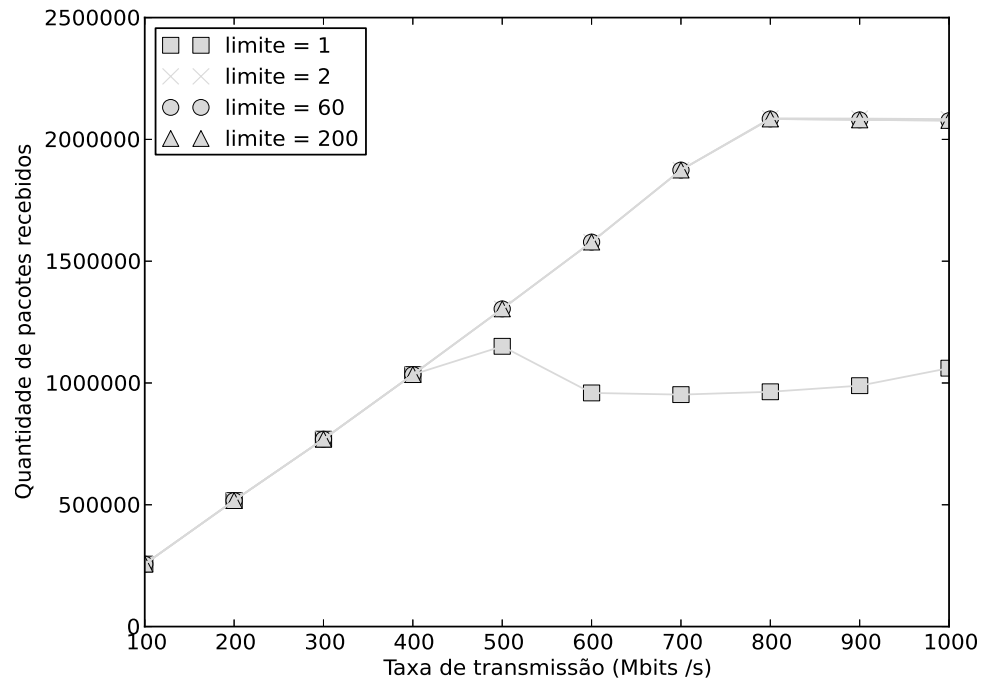

Figura 4.8: Quantidade de pacotes recebidos pelo driver no VirtualBox

\section{Uso de CPU}

No gráfico da Figura 4.9 é plotado o uso de $C P U$ pelas interrupções de software. Notamos que com qualquer limite, houve inicialmente um aumento no uso de $C P U$ até chegar no intervalo entre 90\%-100\% onde o uso permanece entre esses valores e, com exceção da configuração com limite igual a 1, todos tiveram uma redução com taxas de transmissão acima de $700 \mathrm{Mbits} / \mathrm{s}$. Esse comportamento será explicado adiante.

No gráfico da Figura 4.10 é mostrado o uso de $C P U$ dentro da máquina virtual. Com limite igual a 1, a máquina virtual excedeu consideravelmente seu uso em relação aos demais. Isso ocorreu possivelmente porque as interrupções de software chegaram a 100\%. As interrupções de software ocuparam uma $C P U$ inteira enquanto que o iperf ocupou a outra $C P U$.

Já com limites maiores que 1 , o uso de $C P U$ se limitou a 100\%. Isso foi devido tanto ao sistema quanto ao iperf dividirem a mesma $C P U$ e não conseguirem processar os pacotes paralelamente. 


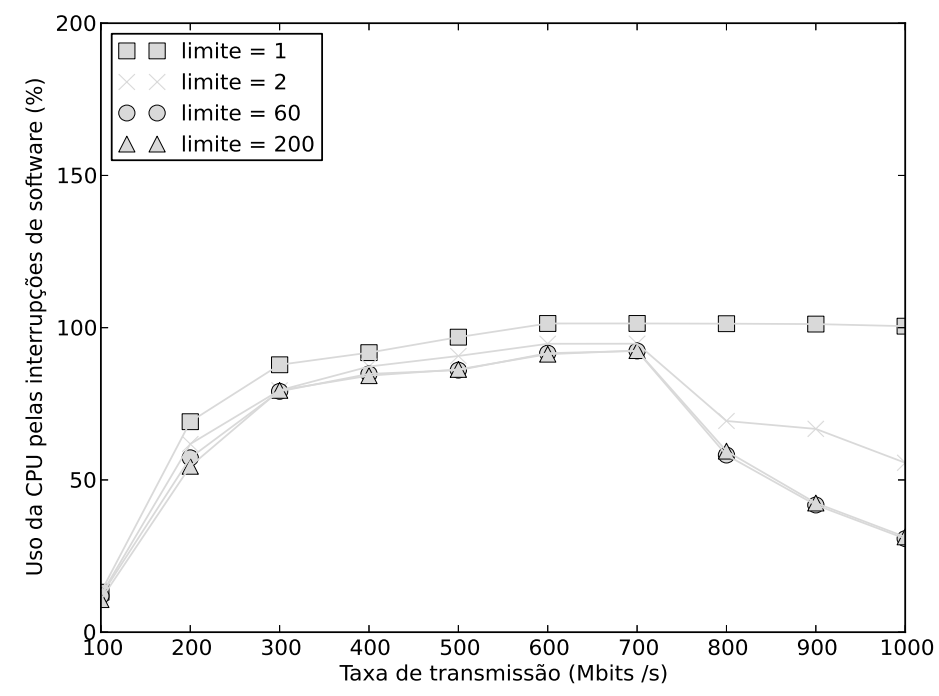

Figura 4.9: Uso da CPU pelas interrupções de software no VirtualBox

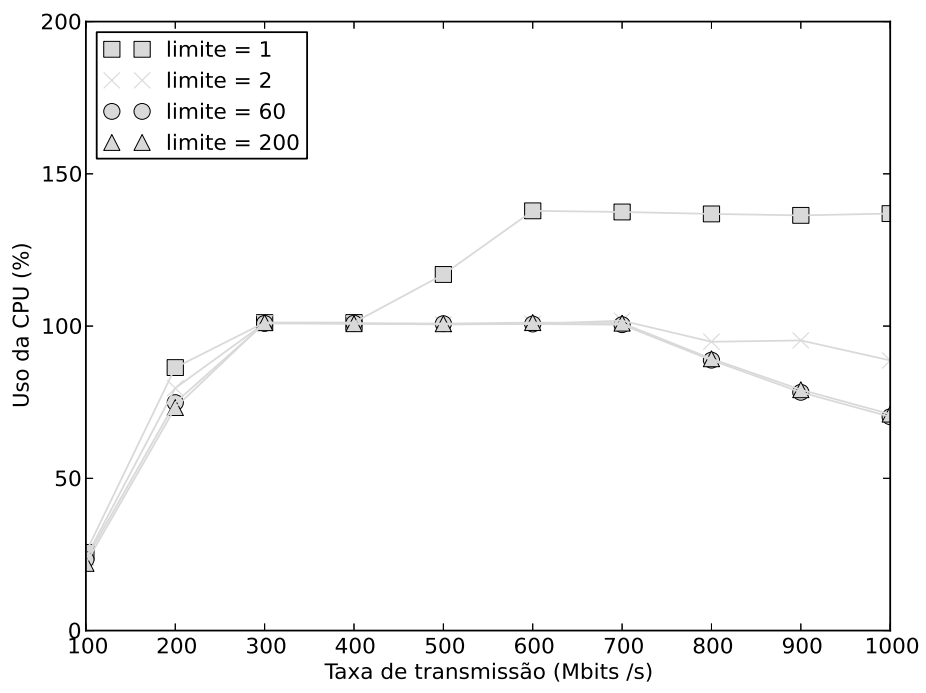

Figura 4.10: Uso da CPU no VirtualBox

Em $300 \mathrm{Mbits} / \mathrm{s}$, o sistema atingiu 100\% e houve perda de pacotes, mas diferentemente do que aconteceu com limite igual a 1, as interrupções não ocuparam $100 \%$ da $C P U$ como mostrado na Figura 4.9. Nesse caso, o sistema perdeu os pacotes no iperf, que divide a $C P U$ com as interrupções, e não conseguiu $C P U$ o suficiente para processar os pacotes. Somente quando a largura de banda de transmissão se aproximou de $800 \mathrm{Mbits} / \mathrm{s}$, o sistema teve uma considerável redução de uso de $C P U$ pelas interrupções de software permitindo o iperf usar mais a $C P U$.

Na gráfico da Figura 4.11 mostramos o uso da $C P U$ da máquina virtual usando o monitor top na máquina física. Comparando com a medição feita dentro da máquina virtual mostrada na Figura 4.10, percebemos que existe uma carga adicional de $C P U$ pela virtualização da máquina. Nesse caso, consideramos o resultado da máquina física, pois a máquina virtual não considera o uso da $C P U$ da emulação do sistema e dos dispositivos de rede. 


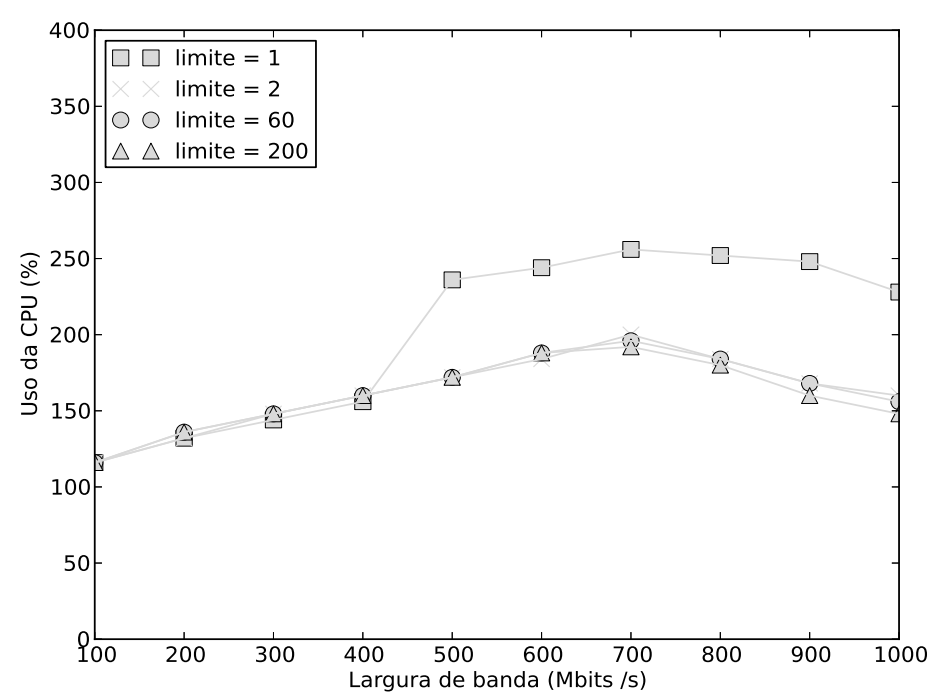

Figura 4.11: Uso da CPU do ponto de vista da máquina física no VirtualBox

\section{Resumo Conclusivo}

Nesse experimento percebemos que uma única $C P U$ é dividida entre as interrupções de software e o iperf, o que causa perda de pacotes no iperf. Vimos que com exceção da configuração com limite igual a 1, todas as outras tiveram uma redução no uso de $C P U$ com transmissão acima de 700 Mbits/s. Isso será melhor analisado no próximo experimento. Também vimos que o processamento das interrupções de software, quando ocupam uma $C P U$ inteira, faz o sistema alocar processos, nesse caso o iperf, para outra $C P U$. Percebemos uma diferença no resultado da medição dentro e fora da máquina virtual e foi considerado o resultado da medição fora da máquina virtual. No próximo experimento separaremos em diferentes CPUs as interrupções de software do iperf para que o sistema possa ter uma melhor utilização da $C P U$. 


\subsubsection{VirtualBox com Afinidade de CPU}

No experimento anterior, vimos que as interrupções de software e o iperf usam a mesma $C P U$ e, como consequência, o iperf não consegue processar todos os pacotes. Assim, temos duas soluções: definir uma $C P U$ para o iperf ser executado ou definir uma $C P U$ para as interrupções. A configuração de associar um processo a uma determinada $C P U$ é chamada de afinidade de $C P U$, já a de associar uma interrupção a uma $C P U$ é chamada de balanceamento de interrupções. Decidimos associar uma $C P U$ para o iperf por ser uma solução simples de ser feita através da ferramenta taskset. Nesse experimento, foram usadas as mesmas configurações de hardware e software do experimento anterior.

\section{Recepção de Pacotes}

Os gráficos das figuras 4.12 e 4.13 mostram respectivamente a taxa de recepção de dados medida pelo iperf e a quantidade de pacotes recebidos pelo driver no VirtualBox. Percebemos que os gráficos são muito semelhantes e não existe uma queda na taxa de recepção como no experimento anterior (Figura 4.7). Notamos também que com limite igual a 1 ainda há perdas de pacotes no driver.

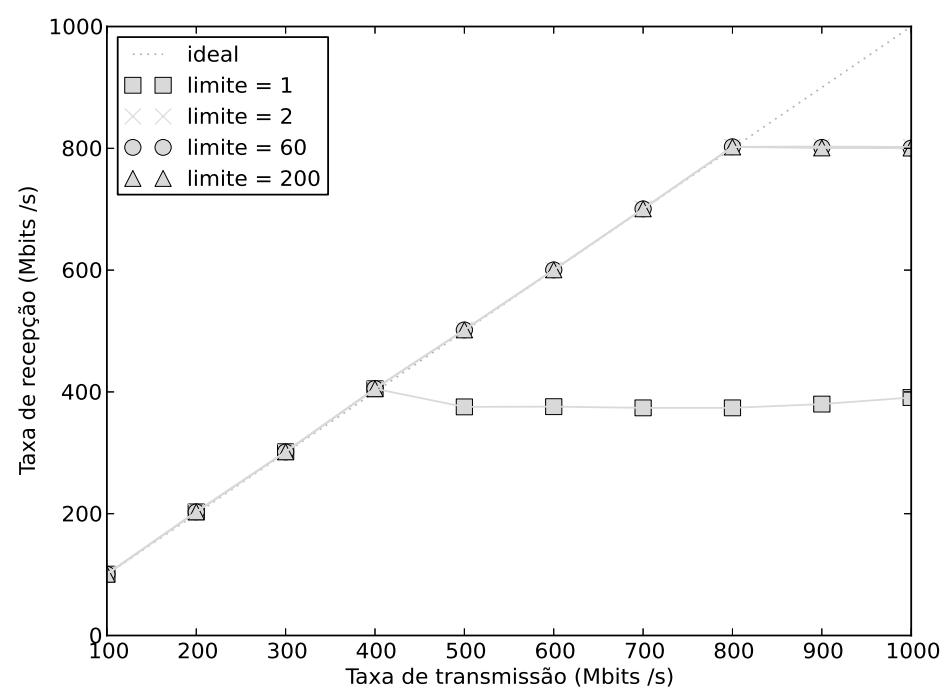

Figura 4.12: Taxa de recep̧ão no VirtualBox com afinidade de $C P U$

\section{Uso de CPU}

No gráfico da Figura 4.14 é mostrado o uso da $C P U$ pelo VirtualBox na máquina física. Vemos que o uso de $C P U$ foi muito maior que em relação ao experimento passado (Figura 4.11) chegando a ultrapassar $200 \%$. Esse aumento foi devido a configuração de afinidade de $C P U$.

Notamos que como no experimento anterior, em transmissões acima de $700 \mathrm{Mbits} / \mathrm{s}$ houve uma redução no uso de $C P U$. Usando o software dmesg, um programa que imprime as mensagens do núcleo do sistema, e modificando o código fonte do driver para imprimir a quantidade de pacotes por ciclo de varredura, veremos a causa dessa redução. Iremos dividir essa explicação em dois cenários: entre $700 \mathrm{Mbits} / \mathrm{s}$ e $800 \mathrm{Mbits} / \mathrm{s}$ e acima de $800 \mathrm{Mbits} / \mathrm{s}$. 


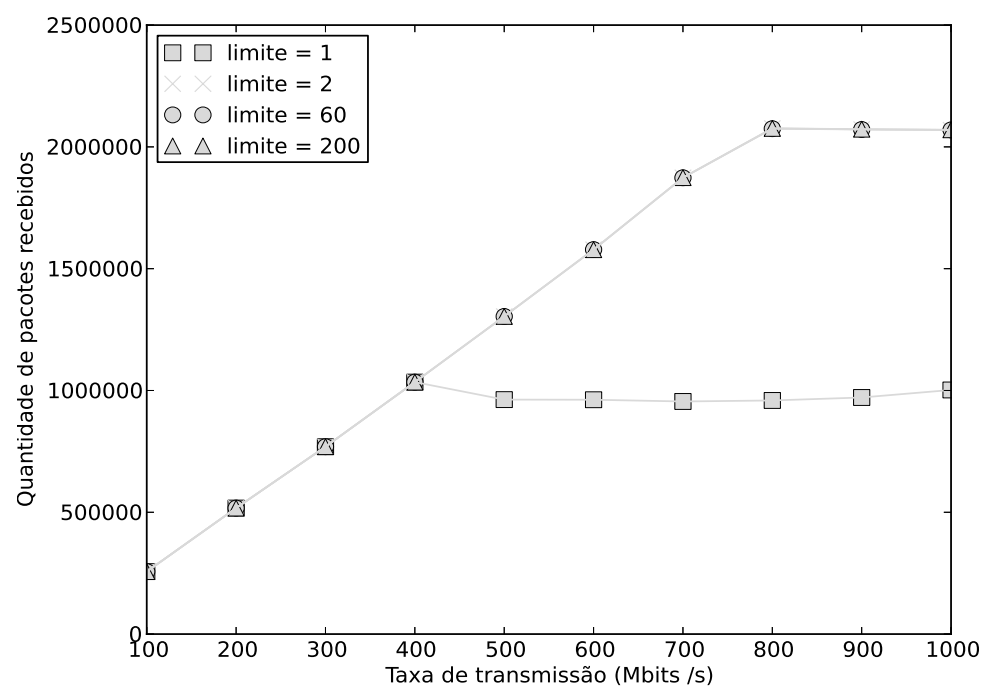

Figura 4.13: Quantidade de pacotes recebidos pelo driver no VirtualBox com afinidade de CPU

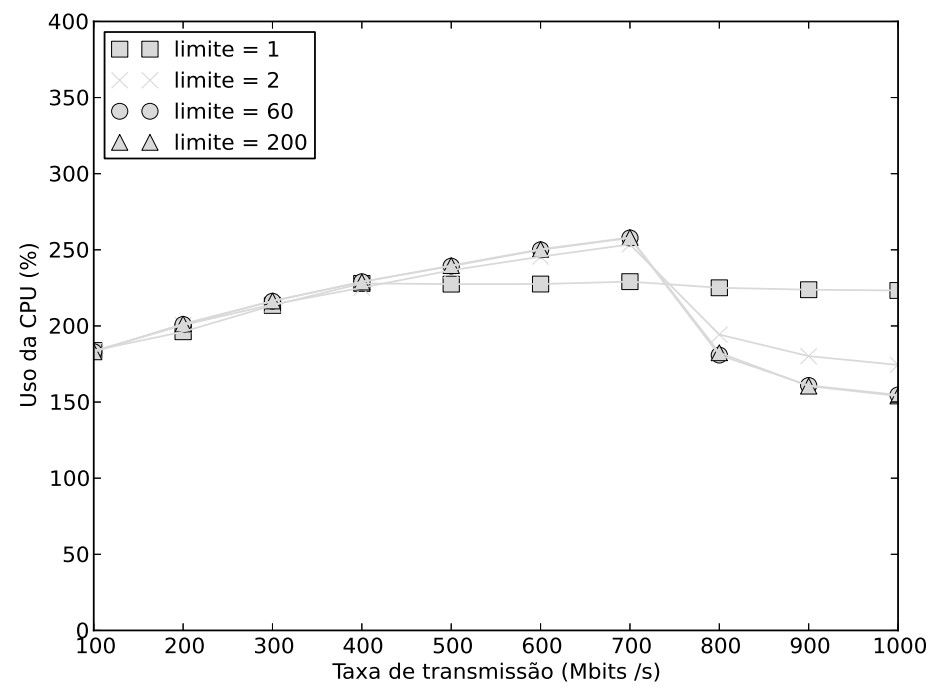

Figura 4.14: Uso da CPU do ponto de vista da máquina física no VirtualBox com afinidade de CPU 
Entre $700 \mathrm{Mbits} / \mathrm{s}$ e $800 \mathrm{Mbits} / \mathrm{s}$, os gráficos das figuras 4.15 e 4.16 mostram a frequência de pacotes processada por ciclo de varredura com limite igual a 60 e respectivamente taxa de transmissão igual a 700 e $800 \mathrm{Mbits} / \mathrm{s}$. Com transmissão de $700 \mathrm{Mbits} / \mathrm{s}$, nota-se que o sistema processa num intervalo entre 5 e 12 pacotes, já com $800 \mathrm{Mbits} / \mathrm{s}$ o sistema passa a processar quantidades maiores de pacotes. Na maioria das vezes continua sendo processados entre 5 e 12 pacotes, mas em frequência menor. Com o aumento de pacotes processados por ciclo de varredura, a quantidade de ciclos para processar todos os pacotes é reduzida e, consequentemente, o uso de $C P U$ pelas interrupções de software.

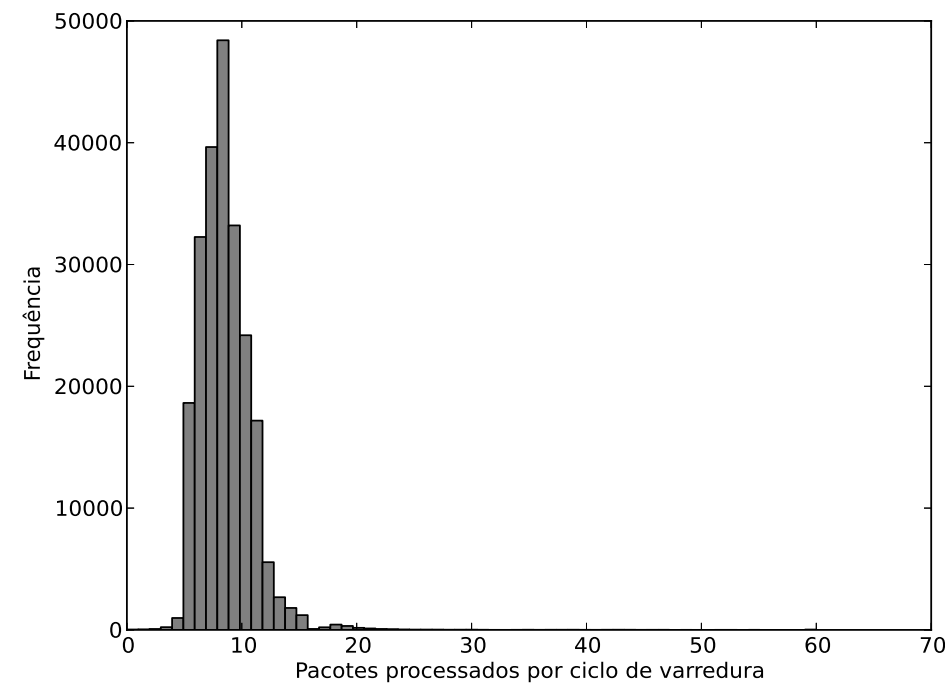

Figura 4.15: Quantidade de pacotes processados por ciclo de varredura com taxa de transmissão de 700 Mbits $/ s$

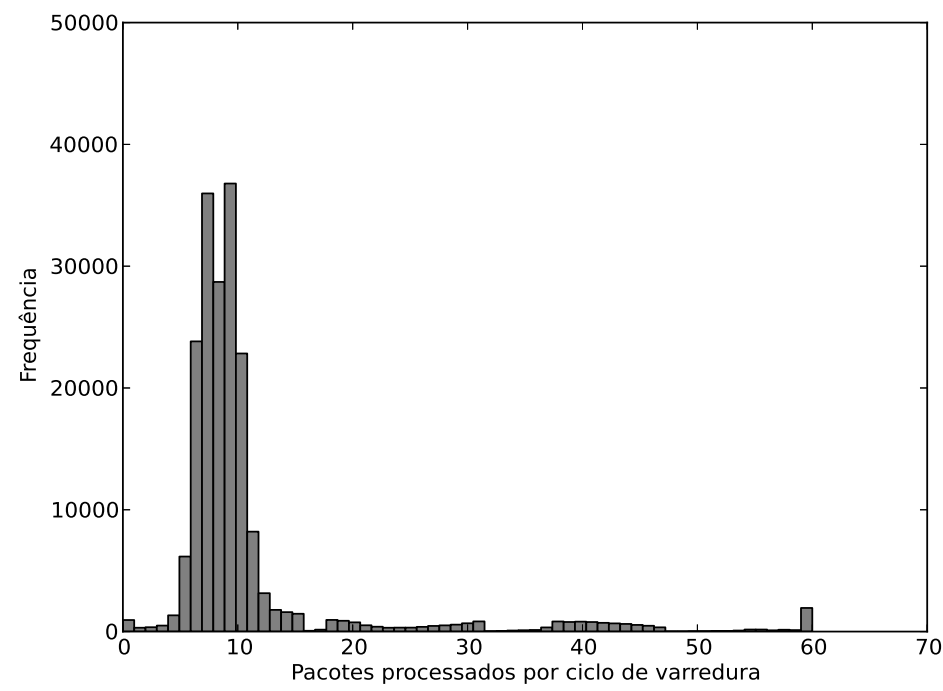

Figura 4.16: Quantidade de pacotes processados por ciclo de varredura com taxa de transmissão de 800 Mbits $/ s$

Com limite igual a 2, o sistema é capaz de processar no máximo 2 pacotes por ciclo. Nesse caso, não teria como reduzir a quantidade de ciclos de varredura, então o sistema processa continuamente os pacotes em vários ciclos contínuos de varredura. Como exemplo, se 10 pacotes foram processados em um ciclo com limite igual a 60, com limite igual a 2, seriam necessários 5 ciclos, em que 2 paco- 
tes serão processados a cada ciclo. Entre ciclos, normalmente o sistema reabilita as interrupções de hardware e espera a chegada de pacotes, mas como o limite de 2 foi atingido e há pacotes esperando serem processados, o sistema não reabilita as interrupções e executa outro ciclo de varredura.

O gráfico da Figura 4.17 plota a taxa de interrupções de hardware por segundo em relação a taxa de transmissão. Com limite igual a 1 e taxa de transmissão igual a $500 \mathrm{Mbits} / \mathrm{s}$ a taxa de interrupções de hardware se aproximou de 0 e, nesse caso, os pacotes foram processados continuamente em vários ciclos de varredura. Consequentemente, a quantidade de tarefas de varredura sobrecarregou o sistema e este passou a descartar pacotes. Com limite igual a 2 a taxa de interrupções não se aproximou de 0, mas comparando com limite igual a 60 e 200, teve maiores agregações de interrupções de hardware, pois muitas vezes o sistema teve que processar em ciclos contínuos de varredura. Com limite igual a 60 e 200 houve uma redução na taxa de interrupções quando a taxa de transmissão foi maior que $800 \mathrm{Mbits} / \mathrm{s}$. Isto pode ser explicado pelos gráficos de frequência de pacotes por ciclo de varredura mostrados nas figuras 4.15 e 4.16. Com o aumento na frequência de pacotes, menos ciclos de varredura são necessários e menor a taxa de interrupções de hardware. Pelos resultados de taxa de recepção e uso de $C P U$ não houve muita diferença entre reduzir a quantidade de ciclos de varredura e agregar as interrupções através de ciclos contínuos de varredura variando o limite.

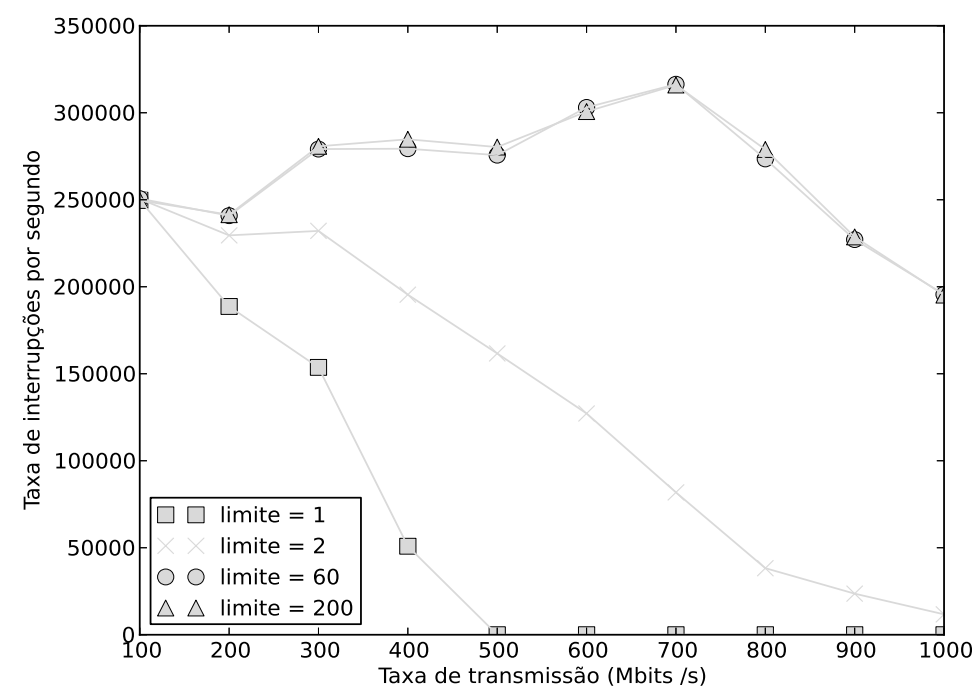

Figura 4.17: Quantidade de interrupções de hardware geradas pela placa de rede virtual no VirtualBox

Voltando a Figura 4.14, acima de $800 \mathrm{Mbits} / \mathrm{s}$ de transmissão, percebe-se que mesmo com o limite de largura de banda de transmissão sendo de $810 \mathrm{Mbits} / \mathrm{s}$, existe uma diferença entre o uso da $C P U$. Na Figura 4.18 é plotada a frequência de pacotes processada por ciclo de varredura com taxa de transmissão igual a $1000 \mathrm{Mbits} / \mathrm{s}$ e limite igual a 60. Observa-se que em relação ao gráfico de $800 \mathrm{Mbits} / \mathrm{s}$, com $1000 \mathrm{Mbits} / \mathrm{s}$, o sistema processou mais pacotes por ciclo de varredura. Um resultado curioso, pois como a transmissão máxima é de $810 \mathrm{Mbits} / \mathrm{s}$, ambos deveriam mostrar resultados semelhantes. Este resultado ocorreu pela forma como o iperf transmite os pacotes. Olhando o código-fonte do iperf, quando se é usado o protocolo UDP, existe um atraso entre envios de pacotes que é calculado pela fórmula:

$$
\text { atraso_entre_envios }=\frac{\text { tamanho_do_pacote }}{\text { taxa_de_transmisso }}+\text { reajuste }
$$

Onde reajuste é um valor definido de acordo com o tempo gasto no laço para transmitir o 
pacote. Assim, quanto maior a taxa de transmissão, menor o atraso entre envios. Quando a taxa de transmissão do iperf é maior que o máximo que o dispositivo de rede é capaz de transmitir, os pacotes são enviados inicialmente em atrasos menores e conforme o dispositivo é sobrecarregado de pacotes para transmitir, o iperf reajusta o valor de atraso. Com esse ajuste dinâmico de envios, é muito provável que ocorram mais rajadas de grande quantidade de pacotes do que se tentasse transmitir com o atraso entre envios constante, o que leva a alterações no desempenho em termos de recepção de pacotes.

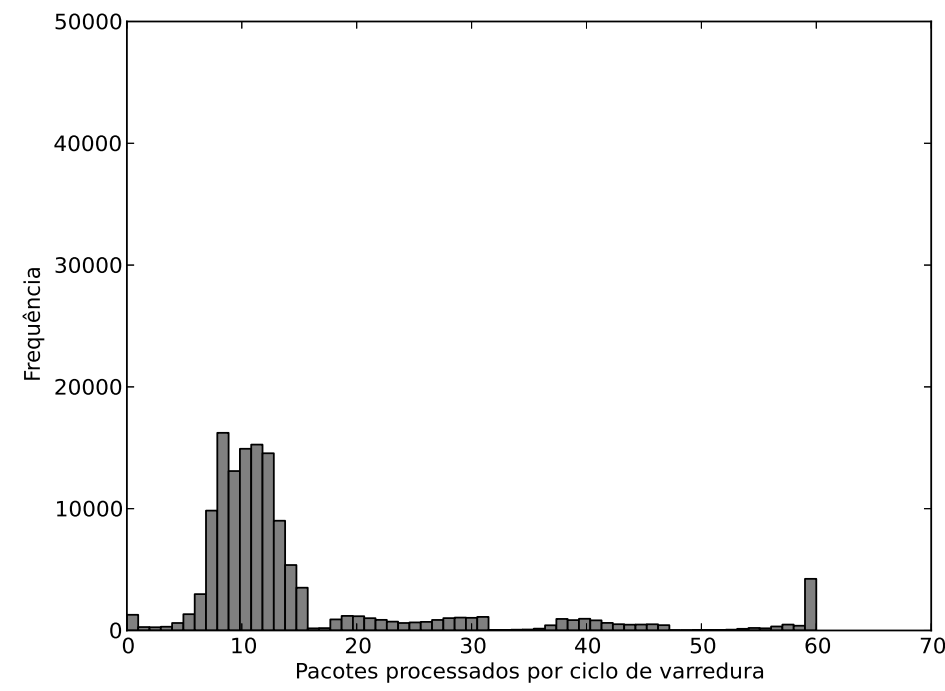

Figura 4.18: Quantidade de pacotes processados por ciclo de varredura com taxa de transmissão de 1000 Mbits/s 


\section{Interrupções de Software}

Nos gráficos das figuras 4.19 e 4.20 são plotados o uso da $C P U$ respectivamente pelas interrupções de software e pelo sistema como um todo. Comparando com os resultados sem afinidade de $C P U$, figuras 4.9 e 4.10, percebemos que o uso de $C P U$ pelas interrupções de software e total foram muito menores. Mas como já foi mostrado na Figura 4.14, o uso da $C P U$ pelo VirtualBox foi muito maior em relação ao experimento anterior. Não foi possível descobrir o motivo do sar mostrar uma redução do uso de $C P U$ dentro da máquina. É possível que seja um problema do próprio VirtualBox.

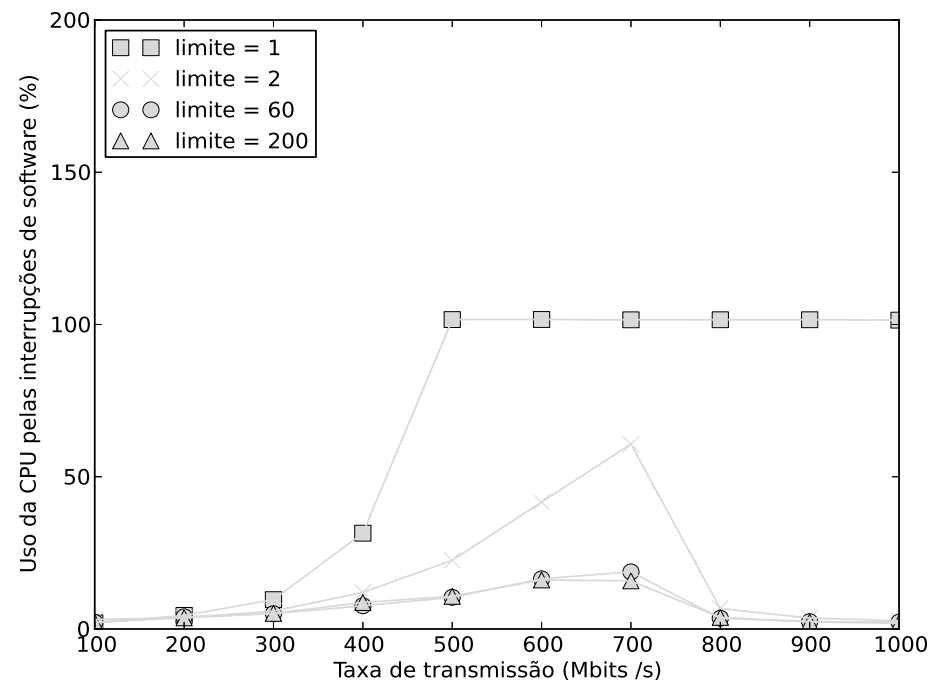

Figura 4.19: Uso da CPU pelas interrupções de software no VirtualBox com afinidade de CPU

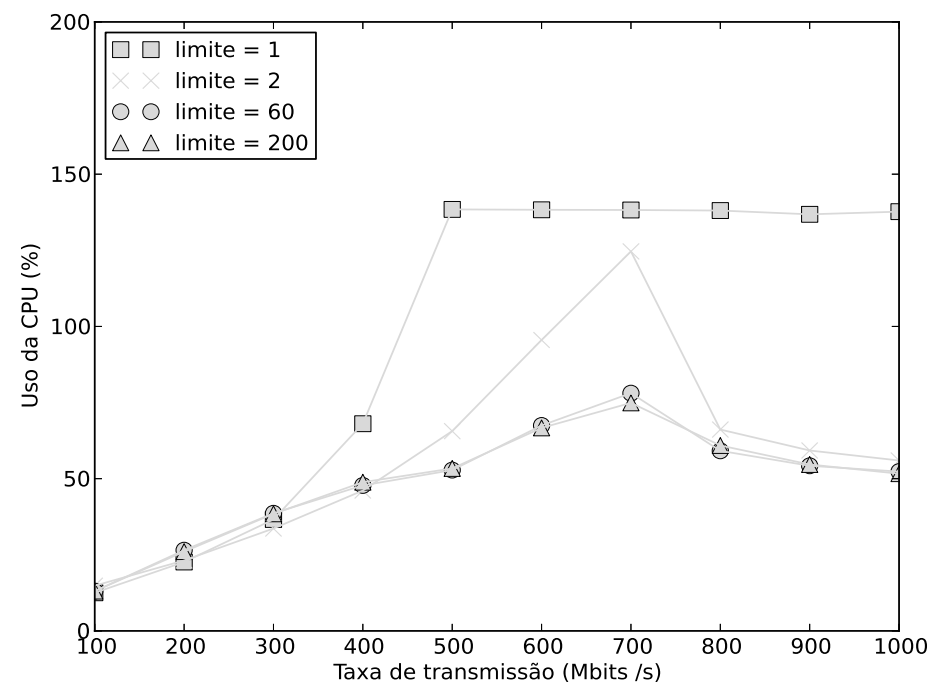

Figura 4.20: Uso da CPU no VirtualBox com afinidade de $C P U$ 


\section{Resumo Conclusivo}

Concluímos que separando o iperf das interrupções em termos de $C P U$, é possível aproveitar melhor a $C P U$ para o processamento de pacotes. Porém, isso gera uma carga extra no processamento, quando não é necessário usar duas $C P U s$. Assim, é interessante saber se os processos usarão mais de uma $C P U$ ou se uma será o suficiente.

Novamente, com exceção do experimento com limite igual a 1, vimos o uso de $C P U$ reduzir entre $700 \mathrm{Mbits} / \mathrm{s}$ e $800 \mathrm{Mbits} / \mathrm{s}$. Há duas explicações: a agregação de interrupções através do processamento contínuo de pacotes e a redução de ciclos de varredura.

Percebemos que o iperf configurado para enviar pacotes em taxas maiores que a capacidade do dispositivo passa a ajustar a transmissão dinamicamente, alterando a frequência de envio e aumentando a quantidade de rajadas longas de pacotes. Nem sempre aplicações com protocolo $U D P$ fazem este tipo de ajuste. Isso provavelmente fez reduzir o uso da $C P U$ com $900 \mathrm{Mbits} / \mathrm{s}$ e $1000 \mathrm{Mbits} / \mathrm{s}$ em relação ao resultado com $800 \mathrm{Mbits} / \mathrm{s}$.

Também concluímos que o parâmetro de limite não afeta a taxa de recepção ou o uso real da $C P U$, a não ser que o valor seja muito baixo. As medições de dentro da máquina virtual não mostraram com precisão o uso da $C P U$ pelas interrupções de software quando usamos duas $C P U s$, não foi possível descobrir a causa. 


\subsubsection{Xen}

Nos experimentos com o Xen, ocorreram as mesmas particularidades relacionadas com o buffer do socket e com o uso da mesma $C P U$ pelo iperf e pelas interrupções de software, como nos experimentos com o VirtualBox. Para resolvê-los, novamente aumentamos o tamanho do buffer e associamos uma $C P U$ para o iperf.

Nos gráficos das figuras 4.21 e 4.22 são plotadas respectivamente a taxa de recepção e a quantidade de pacotes recebidos pelo driver. Ocorreu uma situação semelhante à vista no VirtualBox. Ambos os gráficos ficaram similares para os limites iguais a 2, 60 e 200, e com limite igual a 1 houve perda de pacotes. Porém, ao invés da perda ocorrer quando a transmissão foi maior que 400 Mbits/s esta ocorreu com transmissões maiores que $600 \mathrm{Mbits} / \mathrm{s}$. O limite da transmissão novamente foi próximo de $810 \mathrm{Mbits} / \mathrm{s}$.

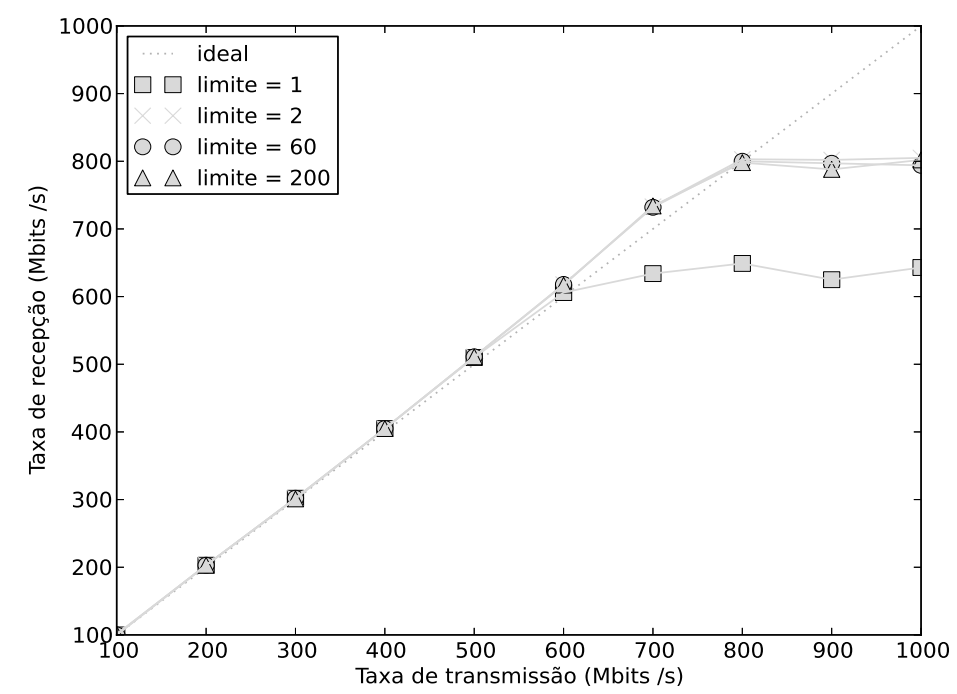

Figura 4.21: Taxa de recepção no Xen

Na Figura 4.23, vemos o uso de $C P U$ da máquina virtual. Esses dados foram obtidos através do xentop, aplicação de monitoramento que o Xen fornece. Percebe-se que o uso de $C P U$ é maior quanto maior o limite, mas entre experimentos com limite igual a 60 ou 200 quase não existe diferença. Nota-se também que o uso de $C P U$ não excedeu 100\%, mas com limite igual a 1 e taxa de transmissão maior que $600 \mathrm{Mbits} / \mathrm{s}$ o sistema parece estar no máximo não conseguindo exceder o uso da $C P U$. Acima de $800 \mathrm{Mbits} / \mathrm{s}$ o sistema parece reduzir pouco o uso da $C P U$.

Nas medições de uso de $C P U$ dentro da máquina virtual ocorreu algo semelhante ao experimento do VirtualBox. Houve uma diferença entre a medição interna e externa. Então, desconsideramos a medição interna.

\section{Resumo Conclusivo}

No Xen percebemos que o uso de $C P U$ por conta do intenso tráfego de rede foi menor do que no VirtualBox. Também notamos que com limite igual a 1, o sistema é capaz de processar mais pacotes. Entre $700 \mathrm{Mbits} / \mathrm{s}$ e $800 \mathrm{Mbits} / \mathrm{s}$ novamente com exceção do experimento com limite igual a 1, houve uma redução no uso da $C P U$ mas muito menor em relação ao VirtualBox. Com limites igual a 1 vimos que novamente houve perda de pacotes já com limite igual a 2 houve um uso maior da $C P U$ em relação aos limites iguais a 60 e 200. 


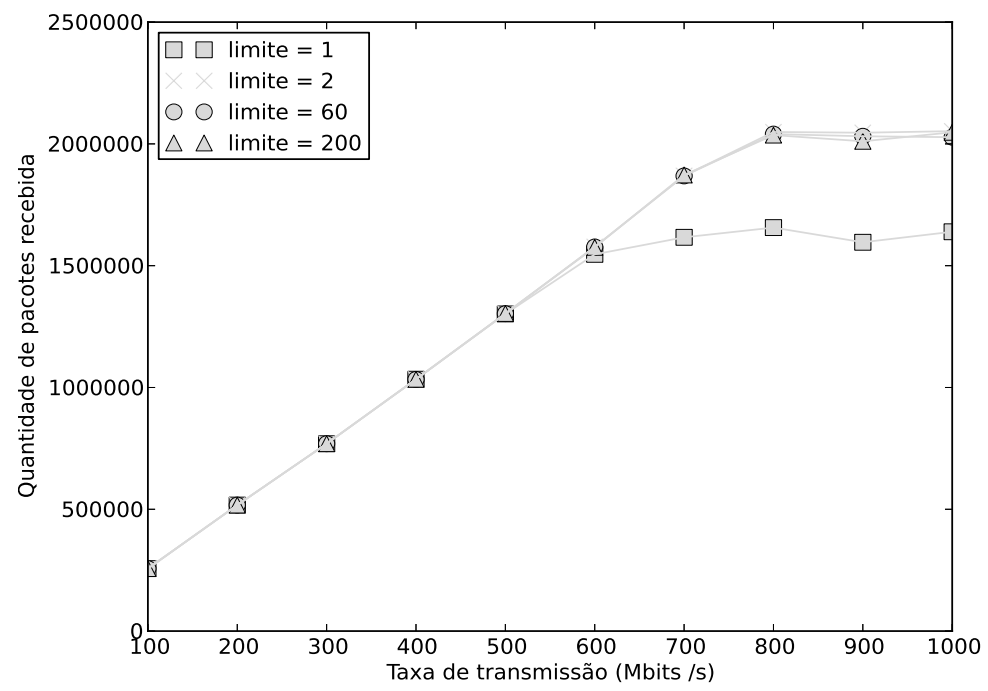

Figura 4.22: Quantidade de pacotes recebidos pelo driver no Xen

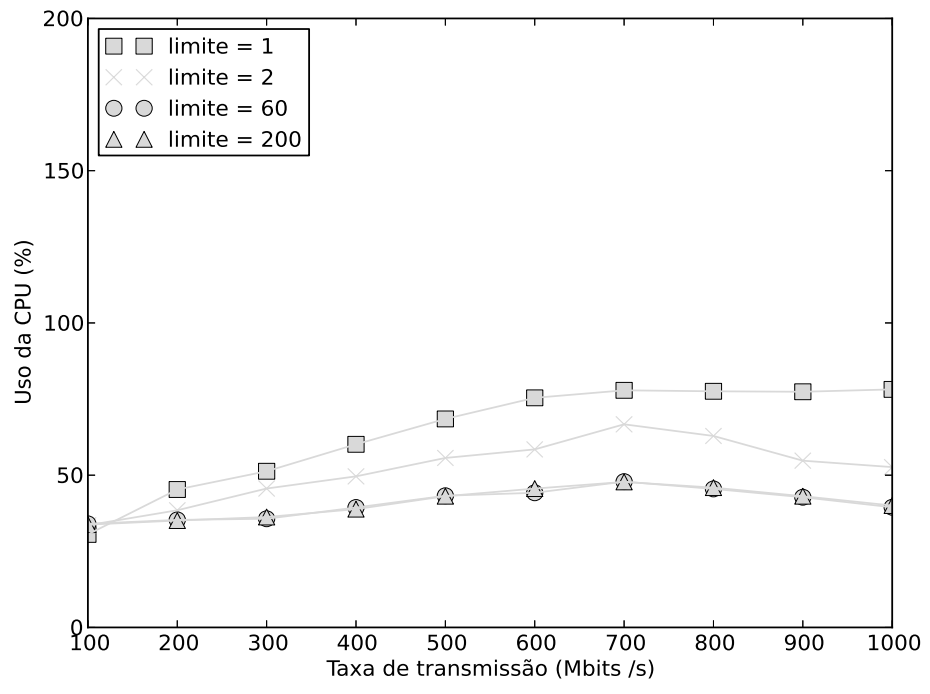

Figura 4.23: Uso da $C P U$ no $X e n$ 


\subsubsection{VMware}

No VMware também houve necessidade de reconfigurarmos o buffer do socket e a afinidade de $C P U$ do iperf.

Nos gráficos das figuras 4.24 e 4.25 são plotadas respectivamente a taxa de recepção e a quantidade de pacotes recebidos pelo driver. Ambos os gráficos ficaram similares. Com limite igual a $1 \mathrm{e}$ 2, houve perda de pacotes quando a taxa de transferência foi maior que $400 \mathrm{Mbits} / \mathrm{s}$. Notamos que houve perda de pacotes com taxa de transmissão maior que $800 \mathrm{Mbits} / \mathrm{s}$. O limite da transmissão, novamente, é próximo de $810 \mathrm{Mbits} / \mathrm{s}$.

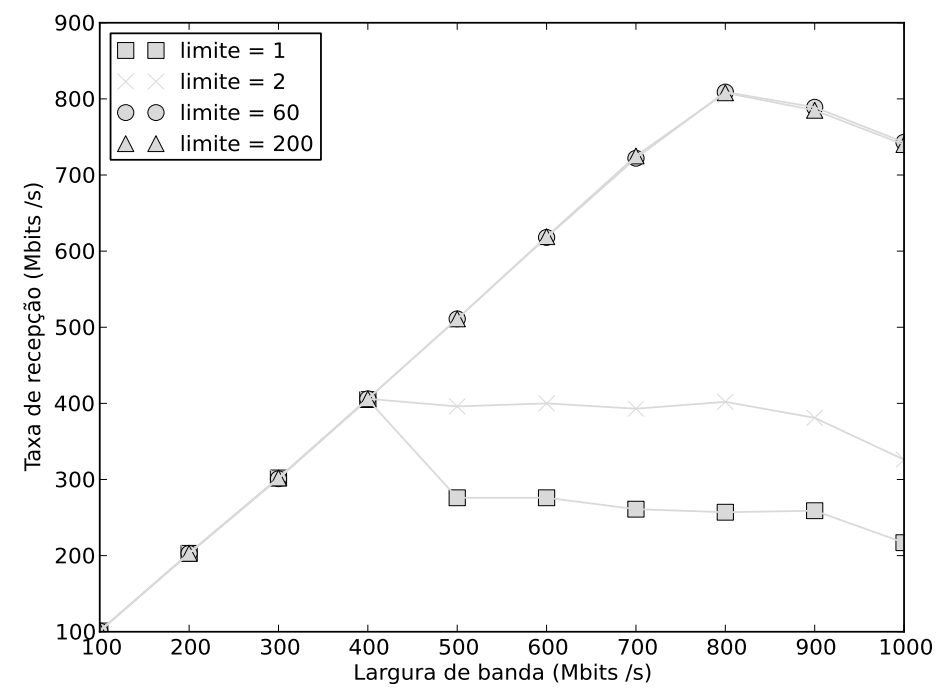

Figura 4.24: Taxa de recepção no VMware

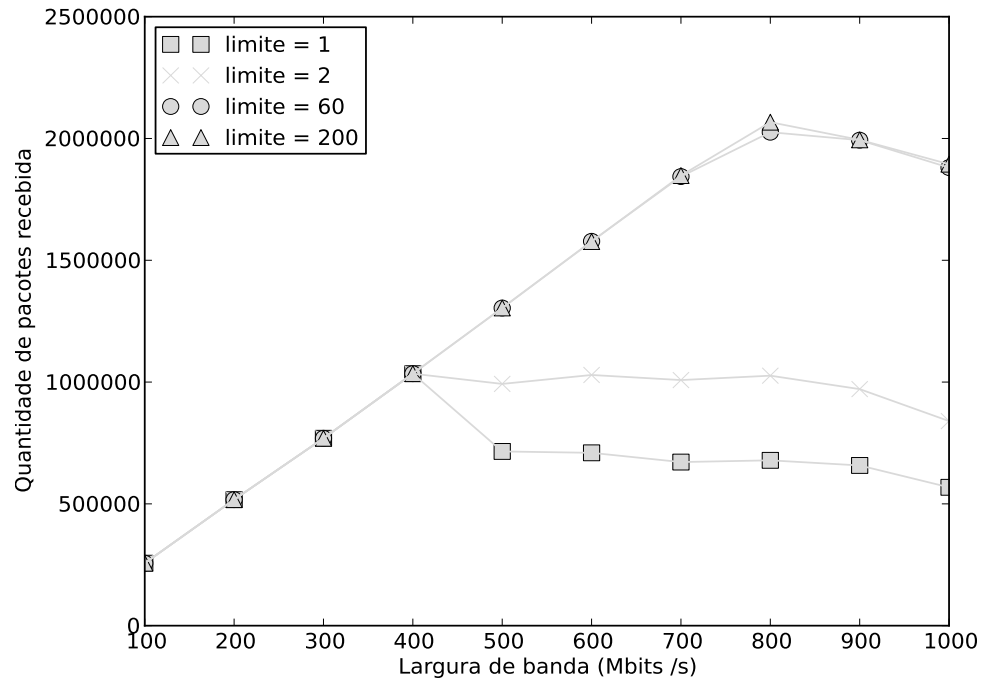

Figura 4.25: Quantidade de pacotes recebidos pelo driver no VMware

No gráfico da Figura 4.26 observamos que o uso de $C P U$ chega ao máximo quando a taxa de 
transmissão é maior que $200 \mathrm{Mbits} / \mathrm{s}$, tendo uma queda entre $700 \mathrm{Mbits} / \mathrm{s}$ e $800 \mathrm{Mbits} / \mathrm{s}$ provavelmente pela alta taxa de transmissão de pacotes. Acima de $800 \mathrm{Mbits} / \mathrm{s}$ nota-se que o uso de $C P U$ não variou.

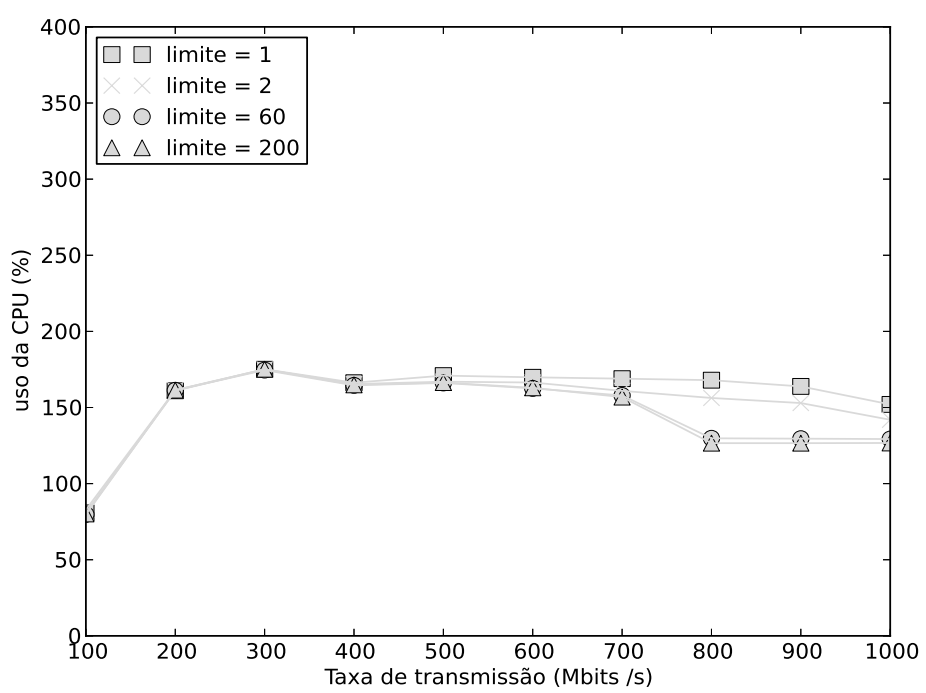

Figura 4.26: Uso da CPU no VMware

\section{Resumo Conclusivo}

Vimos que, com taxa de transmissão maior que $800 \mathrm{Mbits} / \mathrm{s}$, há perda de pacotes, enquanto que nos outros hypervisors, a taxa de recepção permanece constante e o uso de $C P U$ é reduzido. Provavelmente, o sistema não conseguiu processar os pacotes em grandes rajadas. Com limite igual a 1 e 2 houve perda de pacotes com transferência maior que $400 \mathrm{Mbits} / \mathrm{s}$.

\subsection{Análise dos Resultados}

Na Tabela 4.27, são comparados os resultados com os diferentes hypervisors utilizados nos experimentos. Em todos experimentos, tivemos que configurar o tamanho do buffer do socket e selecionar a $C P U$ na qual o iperf seria executado pois isso comprometia as medições. Na prática a não configuração desses parâmetros poderia levar a quedas no desempenho das aplicações.

Em nossos experimentos, percebemos que o parâmetro limite com valores baixos (1 e 2) causou perda de pacotes ou aumento de uso da $C P U$ comparado com os limites altos (60 e 200). Houve um bom desempenho tanto em uso de $C P U$ como taxa de recepção com limites altos na maioria dos casos e não houve diferença no resultado entre limites altos. Na prática não é necessário modificar o parâmetro limite quando usamos o e1000 porque o valor padrão dele é 64 .

Entre 700 e $800 \mathrm{Mbits} / \mathrm{s}$ em todos experimentos, houve uma redução de uso de $C P U$ devido a agregação de interrupções através do processamento contínuo de pacotes e a redução de ciclos de varredura. Valores de taxa de transmissão acima de $800 \mathrm{Mbits} / \mathrm{s}$ causaram um aumento de rajadas longas de pacotes. No VMware, isso gerou perdas de pacotes, no VirtualBox e no Xen houve uma redução de uso de $C P U$. Na prática usar o iperf com UDP e largura de banda acima do limite suportado pelo dispositivo de rede pode gerar resultados inesperados, não sendo recomendado.

Houve uma grande diferença no uso de $C P U$ pelas máquinas virtuais. O VirtualBox foi o que mais gastou $C P U$ com até $270 \%$ de uso. Já o Xen foi o que menos gastou, com até $80 \%$ de uso. Por fim, o VMware gastou até $175 \%$ da $C P U$, porém, ele chegou ao limite de uso de $C P U$ mais 
rápido. Enquanto os outros hypervisors atingiram o máximo com $700 \mathrm{Mbits} / \mathrm{s}$, o VMware atingiu o máximo em $300 \mathrm{Mbits} / \mathrm{s}$.

Em todos os experimentos, medimos a largura de banda pelo iperf. É possível que a medição não tenha a exata precisão já que este faz tanto a geração do tráfego como a contagem de pacotes. Nesse caso, existem alternativas que permitem medições dentro do núcleo do sistema como o net sf s [Lea13]. 


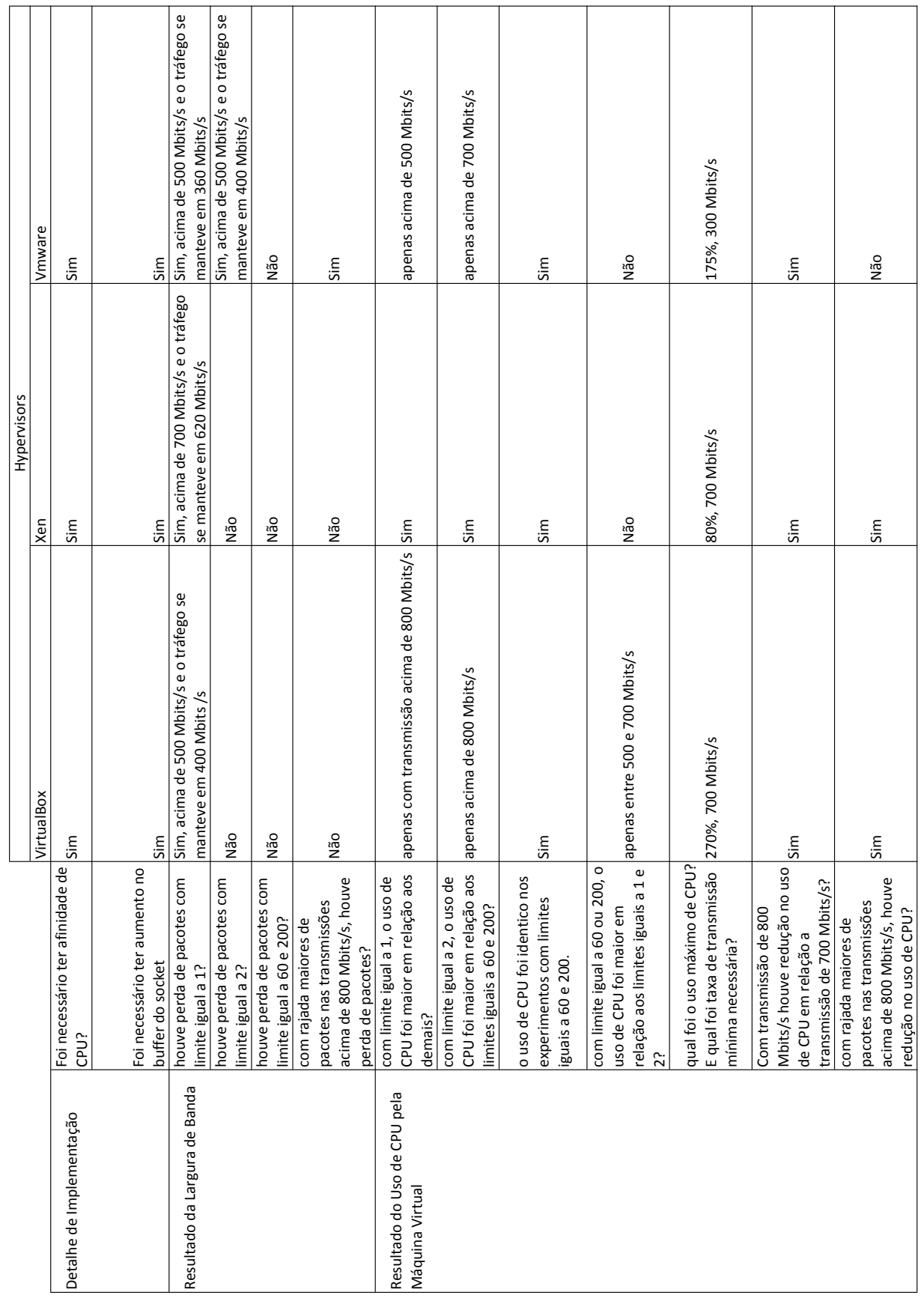

Figura 4.27: Comparação dos resultados com diferentes hypervisors 


\section{Capítulo 5}

\section{Conclusões}

Nessa dissertação tivemos como objetivo elaborar um mecanismo que escolha o melhor valor para o parâmetro limite da NAPI, no qual o sistema tenha um bom desempenho tanto em termos de uso de $C P U$ como na capacidade efetiva da placa de rede. Então, fizemos experimentos analisando o parâmetro limite.

Em nossos experimentos percebemos que o parâmetro limite igual a 1 levou a perda de pacotes. Isso ocorreu devido ao processamento contínuo de pacotes que, quando reduz a taxa de interrupções para próximo de 0, sobrecarrega o sistema com interrupções de software e este passa a descartar pacotes.

Com limite igual a 2, no VirtualBox não houve diferença em relação aos limites 60 e 200. No Xen, o sistema usou mais CPU em relação aos limites 60 e 200. No VMware houve perda de pacotes semelhante ao que ocorreu com limite igual a 1. Com limites altos (60 e 200) houve um bom desempenho tanto em uso de $C P U$ como taxa de recepção e não houve diferença no resultado entre valores altos.

Assim, sabe-se que diferentemente dos dispositivos físicos, que apresentam bom desempenho com limites baixos, nos dispositivos virtuais, limites altos tiveram um bom desempenho em todos os casos comparado com limites baixos. No caso particular, com o e1000, driver usado nos experimentos, o valor de limite por padrão é 64, não sendo necessário um mecanismo para escolher o melhor limite. É importante observar que todas essas conclusões são feitas levando-se em consideração apenas a taxa de recepção percebida pelas aplicações.

Vimos que o uso de $C P U$ é sensível a mudanças na frequência de envio de pacotes mesmo quando a largura de banda não varia. É provável que controlar a frequência de envio de pacotes, aumente a frequência de pacotes processada e, consequentemente, reduza o uso de $C P U$ como ocorreu no VirtualBox e Xen com transmissão acima de $800 \mathrm{Mbits} / \mathrm{s}$.

Quando monitoramos o uso de $C P U$ da máquina virtual com o Xen, VirtualBox e VMware, os resultados mostraram que o Xen foi o que usou menos $C P U$ e teve o melhor desempenho em termos de taxa de recepção.

\subsection{Sugestões para Pesquisas Futuras}

Durante o experimento configuramos o tamanho do buffer do socket. A escolha do valor para esse parâmetro poderia ser automatizado para um valor que não use muita memória e não descarte pacotes. Propor um algoritmo para esse objetivo seria um projeto interessante de pesquisa.

Também selecionamos a $C P U$ na qual o iperf seria executado. Entre usar uma $C P U$ e usar duas, em tarefas que exigem apenas uma $C P U$, houve uma carga extra no processamento quando usamos duas $C P U$. Já com tarefas que exigem duas $C P U s$, experimentos com apenas uma $C P U$ resultou em perda de pacotes. É interessante analisar quando os processos poderão usar uma $C P U$ ou mais e também propor um algoritmo para automatizar essa decisão. 


\section{Referências Bibliográficas}

$\left[\mathrm{AFG}^{+}\right.$09] M. Armbrust, A. Fox, R. Griffith, A.D. Joseph, R.H. Katz, A. Konwinski, G. Lee, D.A. Patterson, A. Rabkin, I. Stoica e M. Zaharia. Above the clouds: A berkeley view of cloud computing. Relatório Técnico UCB/EECS-2009-28, EECS Department, University of California, Berkeley, Feb 2009. 1, 4, 6

[AMN06] P. Apparao, S. Makineni e D. Newell. Characterization of network processing overheads in Xen. Em Proceedings of the 2nd international Workshop on Virtualization Technology in Distributed Computing, página 2. IEEE Computer Society, 2006. 19

$\left[\mathrm{BDF}^{+}\right.$03] P. Barham, B. Dragovic, K. Fraser, S. Hand, T. Harris, A. Ho, R. Neugebauer, I. Pratt e A. Warfield. Xen and the art of virtualization. SIGOPS Oper. Syst. Rev., 37(5):164-177, Outubro 2003. 1, 6, 18

[BM99] S. Bradner e J. Mcquaid. RFC 2544-benchmarking methodology for network interconnect devices. http://www.ietf.org/rfc/rfc2544.txt, 1999. Acessado em: 8/8/2013. 9

[Cor05] J. Corbet. NAPI performance - a weighty matter. http://lwn.net/Articles/139884/, 2005. Acessado em: 8/8/2013. 2, 23

[Cor09] J. Corbet. Generic receive offload. http://lwn.net/Articles/358910/, 2009. Acessado em: 8/8/2013. 14,15

[Cor12] J. Corbet. Software interrupts and realtime. https://lwn.net/Articles/520076/, 2012. Acessado em: 8/8/2013. 11

[CRKH05] J. Corbet, A. Rubini e G. Kroah-Hartman. Linux Device Drivers, páginas 497-595. O'Reilly Media, 3 edição, 2005. 2, 13, 14

[CSYL10] J. Che, C. Shi, Y. Yu e W. Lin. A synthetical performance evaluation of OpenVZ, Xen and KVM. Em Proceedings of the 2010 IEEE Asia-Pacific Services Computing Conference, APSCC '10, páginas 587-594, Washington, DC, USA, 2010. IEEE Computer Society. 7

[DXZL11] Y. Dong, D. Xu, Y. Zhang e G. Liao. Optimizing network I/O virtualization with efficient interrupt coalescing and virtual receive side scaling. Em Proceedings of the 2011 IEEE International Conference on Cluster Computing, CLUSTER '11, páginas 26-34, Washington, DC, USA, 2011. IEEE Computer Society. 1, 12

[Eas07] T. Eastep. Xen network environment. http://www1.shorewall.net/XenMyWay.html, 2007. Acessado em: 8/8/2013. vii, 9, 10

[EF10] J. Ekanayake e G. Fox. High performance parallel computing with clouds and cloud technologies. Em Cloud Computing, páginas 20-38. Springer Berlin Heidelberg, 2010. $1,8,17$ 
[FA12] T. Fortuna e B. Adamczyk. Improving packet reception and forwarding within virtualized Xen environments. Em Computer Networks, páginas 153-160. Springer, 2012. 19

[GED $\left.{ }^{+} 11\right]$ G.E. Gonçalves, P.T. Endo, T. Damasceno, A.V.A.P. Cordeiro, D. Sadok, J. Kelner, B. Melander e J.E. Mångs. Resource allocation in clouds: Concepts, tools and research challenges. Simpósio Brasileiro de Rede de Computadores, 2011. 1, 7

[Int07] Intel. Interrupt moderation, Intel gbe controllers. http://www.intel.com/content/www/ us/en/ethernet-controllers/gbe-controllers-interrupt-moderation-appl-note.html, 2007. Acessado em: 8/8/2013. 20, 21

[Int11] Intel. Linux ixgbe* base driver overview and installation. http://www.intel.com/ support/network/adapter/pro100/sb/CS-032530.htm, 2011. Acessado em: 8/8/2013. 21

[Jam04] T.Y. James. Performance evaluation of Linux bridge. http://facweb.cti.depaul.edu/ jyu/Publications/Yu-Linux-TSM2004.pdf, 2004. Acessado em: 8/8/2013. 10

[JSJK11] J.W. Jang, E. Seo, H. Jo e J.S. Kim. A low-overhead networking mechanism for virtualized high-performance computing systems. The Journal of Supercomputing, páginas 1-26, 2011. 19

[Lea13] B. Leal. netsfs. http://www.ime.usp.br/ beraldo/netsfs/, 2013. Acessado em: 6/12/2013. 43

[Liu10] J. Liu. Evaluating standard-based self-virtualizing devices: A performance study on 10 gbe NICs with SR-IOV support. Em IEEE International Parallel \&s Distributed Processing Symposium (IPDPS), páginas 1-12. IEEE, 2010. 1, 8, 18

[MCZ06] A. Menon, A.L. Cox e W. Zwaenepoel. Optimizing network virtualization in Xen. Em Proceedings of the annual conference on USENIX'06 Annual Technical Conference, páginas 2-2. USENIX Association, 2006. 14

[ON09] H. Oi e F. Nakajima. Performance analysis of large receive offload in a Xen virtualized system. Em International Conference on Computer Engineering and Technology, 2009 (ICCET'09), volume 1, páginas 475-480. IEEE, 2009. 19

$\left[\mathrm{PZW}^{+}\right.$07] P. Padala, X. Zhu, Z. Wang, S. Singhal, K.G. Shin et al. Performance evaluation of virtualization technologies for server consolidation. HP Laboratories Technical Report, 2007. 7

[Rix08] S. Rixner. Network virtualization: Breaking the performance barrier. Queue, 6(1):37:3637:ff, Janeiro 2008. 1, 7, 9, 17

[Sal07] K. Salah. To coalesce or not to coalesce. AEU-International Journal of Electronics and Communications, 61(4):215-225, 2007. 1, 12, 20, 21

[SBdSC] A.H. Schmidt, M.P. Boufleur, R.C.M. dos Santos e A.S. Charao. Análise de desempenho da virtualização de rede nos sistemas Xen e OpenVZ. http://www-usr.inf.ufsm.br/ canofre/site/arquivos/2007/errc_07_ap.pdf. Acessado em: 8/8/2013. 7

[SEB05] K. Salah e K. El-Badawi. Analysis and simulation of interrupt overhead impact on OS throughput in high-speed networks. International Journal of Communication Systems, 18(5):501-526, 2005. 2, 11, 19, 20

[Spe10] S. Spector. New to Xen guide. http://www.xen.org/files/Marketing/NewtoXenGuide. pdf, 2010. Acessado em: 8/8/2013. 9 
[SQ09] K. Salah e A. Qahtan. Implementation and experimental performance evaluation of a hybrid interrupt-handling scheme. Computer Communications, 32(1):179-188, 2009. $20,21,23$

[Sta10] W. Stallings. Computer organization and architecture, páginas 195-232. Pearson Education India, 8 edição, 2010. vii, 3, 5, 9, 11, 12

[STJP08] J. Santos, Y. Turner, G. Janakiraman e I. Pratt. Bridging the gap between software and hardware techniques for I/O virtualization. Em USENIX 2008 Annual Technical Conference on Annual Technical Conference, ATC'08, páginas 29-42, Berkeley, CA, USA, 2008. USENIX Association. vii, 7, 9, 10, 11, 18

[WCC $\left.{ }^{+} 08\right]$ J.P. Walters, V. Chaudhary, M. Cha, S.G. Jr. e S. Gallo. A comparison of virtualization technologies for HPC. Em Proceedings of the 22nd International Conference on Advanced Information Networking and Applications, AINA '08, páginas 861-868, Washington, DC, USA, 2008. IEEE Computer Society. 1, 6, 7, 8, 17

[WR12] C. Waldspurger e M. Rosenblum. I/O virtualization. Communications of the ACM, 55(1):66-73, 2012. 1, 8, 18 